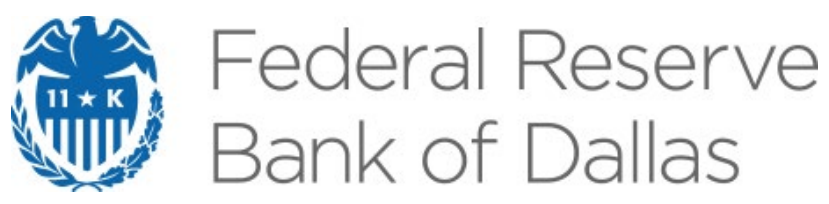

\title{
Shock-Dependent Exchange Rate Pass-Through: Evidence Based on a Narrative Sign Approach
}

Lian An, Mark A. Wynne and Ren Zhang

Globalization Institute Working Paper 379

Research Department

https://doi.org/10.24149/gwp379

Working papers from the Federal Reserve Bank of Dallas are preliminary drafts circulated for professional comment. The views in this paper are those of the authors and do not necessarily reflect the views of the Federal Reserve Bank of Dallas or the Federal Reserve System. Any errors or omissions are the responsibility of the authors. 


\title{
Shock-Dependent Exchange Rate Pass-Through: Evidence Based on a Narrative Sign Approach ${ }^{*}$
}

\author{
Lian $\mathrm{An}^{\dagger}$, Mark A. Wynne ${ }^{\ddagger}$ and Ren Zhang ${ }^{\S}$ \\ First Draft: March 20, 2019 \\ Current Draft: January 28, 2020
}

\begin{abstract}
This paper studies shock-dependent exchange rate pass-through for Japan with a Bayesian structural vector autoregression model. We identify the shocks by complementing the traditional sign and zero restrictions with narrative sign restrictions related to the Plaza Accord. We find that the narrative sign restrictions are highly informative, and substantially sharpen and even change the inferences of the structural vector autoregression model originally identified with only the traditional sign and zero restrictions. We show that there is a significant variation in the exchange rate pass-through across different shocks. Nevertheless, the exogenous exchange rate shock remains the most important driver of exchange rate fluctuations. Finally, we apply our model to "forecast" the dynamics of the exchange rate and prices conditional on certain foreign exchange interventions in 2018, which provides important policy implications for our shock-identification exercise.
\end{abstract}

JEL Classification: E31, F31, F41

Keywords: Exchange Rate Pass-Through, Inflation Forecasting, Narrative Sign Restrictions, Structural Scenario Analysis.

\footnotetext{
*We would like to thank Nathan Balke, Barthelemy Bonadio, Roberto Duncan, Pavel Kapinos, Lutz Kilian, Xiao Wang, and Hakan Yilmazkuday for helpful discussions and suggestions. We also thank Juan Antolín-Díaz, Davor Kunovac, Tsvetelina Nenova, and Juan Rubio-Ramírez for generously sharing their Matlab code with us. Summer McVicker and Amro Shohoud provided excellent research assistance. Ren Zhang gratefully acknowledges the hospitality of the Federal Reserve Bank of Dallas Research Department while working on this project. All remaining errors are ours alone. The views expressed in this paper are ours alone and do not necessarily reflect the views of the Federal Reserve Bank of Dallas, or the Federal Reserve System.

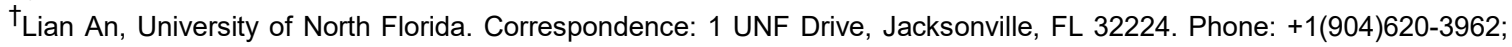
Fax: +1(904)620-2640; E-mail: lian.an@unf.edu.

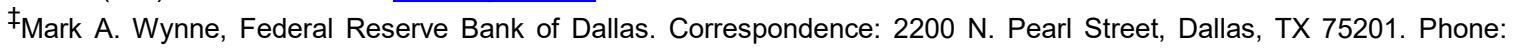
+1(214)922-5159; Fax: +1(214)922-5194; E-mail: mark.a.wynne@dal.frb.org.

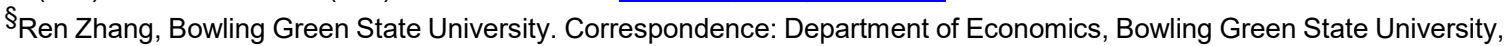
Bowling Green, $\mathrm{OH}$ 43403. Phone: +1(419)372-2640. Fax: +1(419)372-1557. E-mail: renz@bgsu.edu. Webpage: https://renzhang.weebly.com.
} 


\section{Introduction}

Exchange rates play a crucial role in the global transmission of macroeconomic shocks. The extent to which exchange rate movements affect domestic prices, a phenomenon known as exchange rate pass-through (ERPT), lies at the heart of various academic debates and has significant implications for economic policy. There is an extensive literature showing that the degree of ERPT has critical implications for a wide array of macroeconomic policy issues, including the international transmission of monetary shocks (Betts and Devereux 2000), the optimal conduct of domestic monetary policy (Adolfson 2001; Smets and Wouters 2002; Monacelli 2005; Sutherland 2005; Corsetti et al. 2008), the choice of exchange rate regime (Engel 2002 and Devereux and Engel 2003), and the adjustment of global trade imbalances (Obstfeld 2002). A recent strand of the ERPT literature, pioneered by Shambaugh (2008) and Forbes et al. (2018a), shows with a structural vector autoregression (SVAR) model that ERPT is shock-dependent, with the extent of ERPT depending on the types of exogenous shocks that trigger the exchange rate movements. This finding is subsequently confirmed by studies such as Borensztein and Queijo Von Heideken (2016) for six South American countries, Comunale and Kunovac (2017) for the euro area, Corbo et al. (2018) for Sweden, Forbes et al. (2018b) for twenty-six advanced economies, Comunale (2019) for three Baltic states and Ha et al. (2019) for a collection of forty-seven countries around the world.

As with all SVAR studies, shock identification is pivotal for correct inference on the degree of shock-dependent ERPT. Forbes et al. (2018a) identify the structural shocks with a combination of zero and sign restrictions on the impulse responses. ${ }^{1}$ Subsequent studies apply similar identification strategies to many other countries. While the minimalist sign restrictions imposed on impulse responses are generally weaker than classical identification schemes, and thus more likely to be agreed upon by many researchers, they are not without problems. This type of sign restriction, which we will refer to as the traditional sign restriction in this paper, will usually result in a set of structural parameters with very different implications for impulse response functions, elasticities, historical decompositions, and forecasting error variance decompositions. As such, it can be difficult to arrive at meaningful economic conclusions. Furthermore, the procedure may retain draws in the admissible set structural parameters with implausible implications (Antolín-Díaz and Rubio-Ramírez 2018). This could especially distort the inference of the shock-dependent ERPT defined as the ratio of the impulse responses of prices to the impulse responses of the exchange rates to the same shock. In particular, the shock-dependent ERPT ratios are usually estimated with wide confidence bands in Forbes et al. (2018a) and many other studies. The key research question that still remains is how to improve ERPT estimation based on SVAR models identified with the traditional sign and zero restrictions?

Against this backdrop, this paper attempts to estimate the shock-dependent ERPT ratios

\footnotetext{
${ }^{1}$ Earlier studies in the shock-dependent ERPT literature, such as Shambaugh (2008) and Borensztein and Queijo Von Heideken (2016), make use of either contemporaneous or long-run zero restrictions to identify the structural shocks. The pure zero restriction approach has the important disadvantage of imposing stringent restrictions that can have a significant impact on the estimated results. Some assumptions may be developed over time in a data-mining like manner where researchers look for restrictions that can provide sensible results (and) that conform to prior beliefs, as point out by Rudebusch (1998), and more recently by Baumeister and Hamilton (2019) and Zhang (2019).
} 
to import prices and consumer prices for Japan from 1980M2 to 2017M12 with an alternative identification strategy. ${ }^{2}$ We identify the structural shocks by complementing the traditional sign and zero restrictions approach (largely following Forbes et al. (2018a)) with the narrative sign restrictions approach proposed by Antolín-Díaz and Rubio-Ramírez (2018). Narrative sign restrictions are sign restrictions derived from established narrative information, which allow researchers to restrict the sign of specific structural shocks and/or historical decompositions to be compatible with the established narrative account of a single or a series of key historical events. The idea, as stated in Antolín-Díaz and Rubio-Ramírez (2018), is to "come up with a small number of additional uncontentious sign restrictions that help shrink the set of admissible structural parameters and allow us to reach clear economic conclusions." The specific narrative sign restrictions that we impose in this paper are that the exchange rate shock is a yen-appreciation shock which also contributes more to the variation of the Japanese exchange rate compared to other shocks around October 1985 after the Plaza Accord was signed. The Plaza Accord of 1985 makes Japan particularly well suited to our procedure. We estimate the SVAR model with Bayesian methods and identify six structural shocks (a supply shock, a demand shock, a monetary policy shock, an exchange rate shock, a persistent foreign export price shock, and a transitory foreign export price shock) with an algorithm that combines the procedure developed in Arias et al. (2018) and the approach introduced in Antolín-Díaz and Rubio-Ramírez (2018).

Our empirical analysis leads to the following novel findings. First, the narrative sign restrictions improve the shock identification compared with the traditional methodology along three dimensions, i.e., impulse response, shock distribution, and counterfactual analysis. The narrative sign restrictions efficiently reduce the uncertainty of the impulse responses to the supply shock, demand shock, and exchange rate shock, even if we only impose the narrative information associated with the Plaza Accord in a single month. Moreover, we examine the distributions of the exchange rate shock and the counterfactual exchange rate paths if no structural shocks other than the exchange rate shock had occurred for three selected months with heavy foreign exchange interventions, i.e., October 1985, July 1989, and March 2004. Based on the narrative sign approach, we find that the exchange rate shocks mostly fall into the domains consistent with historical records of interventions and contribute a majority of the variation in the exchange rate for these three episodes. By contrast, when identifying shocks with the traditional sign and zero restrictions, the exchange rate shocks are almost evenly distributed around zero and contribute modestly to exchange rate movements. This suggests that the identification fails to detect the interventions without the information from the narrative sign restrictions. The narrative-sign-identified exchange rate shock is more consistent with reality.

Second, we confirm that the estimates of ERPT ratios to both import prices and consumer

\footnotetext{
${ }^{2}$ The case of Japan is especially interesting. The yen is classified as freely floating currency since 1977 in Ilzetzki et al. (2019). The value of the yen has exhibited significant variation in the past decades. In 2013, Japan has set $2 \%$ inflation target as a yardstick to end the deflation gripped Japan for years. During the past seven years, despite the unprecedented massive monetary stimulus program and the depreciated yen, the inflation target remains elusive and irrelevant. Given that Japan is with a high degree of openness, studying the ERPT for Japan yields stark and timely implication for Japan's inflation target and the appropriate monetary and foreign exchange policy.
} 
prices vary substantially in Japan depending on the sources of the shocks behind the exchange rate movements. Taking into account the fact that the composition of economic shocks driving the exchange rate evolves over time, we show that the shock-dependent ERPT helps explain why the degree of ERPT in Japan has shifted significantly in recent decades as documented in Hara et al. (2015). This highlights the necessity of studying ERPT conditional on different shocks. Nevertheless, we argue that the ERPT conditional on the exogenous exchange rate shock deserves special attention because it contributes over $60 \%$ of the variation of the exchange rate when narrative sign restrictions are imposed. On the contrary, when adopting only the traditional sign and zero restrictions, the exchange rate shock explains no more than $28 \%$ of the variance in the exchange rate while the demand shock contributes more, as in Comunale and Kunovac (2017) and Forbes et al. (2018a). Given that the contribution of other shocks is similar across the identification strategies, we infer that previous studies might have underestimated the importance of the exchange rate shock because the identification strategies are not strong enough to differentiate the exchange rate shock from the demand shock without the narrative sign restrictions. The evidence based on the narrative sign approach is consistent with Farrant and Peersman (2006) which suggests that the exchange rate is more of a source of shocks than a shock absorber. When focusing on the exchange rate shock, we find that the narrative sign restrictions are highly informative, which sharpen and even change the inference of the ERPT ratios. In particular, the range of the $68 \%$ confidence band of the ERPT ratios conditional on the exchange rate shock shrinks by over $70 \%$ when incorporating the narrative sign restrictions. The pass-through from the exogenous exchange rate shock to import prices is incomplete in both short-run and long-run. The median short-run ERPT to import prices estimated by the narrative sign approach is lower than the share of imports invoiced in producer currency while the same ERPT estimated by the traditional approach is higher than the share of producer currency pricing. We use the model in Burstein and Gopinath (2014) to show that the short-run ERPT estimated by the narrative sign approach suggests that foreign exporting firms choose to lower their prices when the foreign currency appreciates while the traditional approach suggests the opposite. Similarly, the median long-run ERPT ratios to both import prices and consumer prices are also lower than their counterparts in the model without the narrative sign restrictions.

Third, we evaluate the policy implications of our findings with the novel structural scenario analysis of Antolin-Diaz et al. (2018). The structural scenario analysis is essentially a forecasting exercise conditional on structural shocks, which highlights the effectiveness of the narrative sign identification approach in practical policy-making. We forecast the potential paths of import prices and consumer prices in the first half of 2018 under two different scenarios: (a) if the Ministry of Finance in Japan had targeted a fixed exchange rate using unanticipated foreign exchange interventions; ${ }^{3}$ (b) if the Ministry of Finance had targeted a $2 \%$ import price inflation rate by unexpected foreign exchange interventions. We show that the Ministry of Finance needs moderate interventions to achieve the targets in both scenarios, which generates a series of shocks that depreciate the yen by between $0.15 \%$ and $1.3 \%$ (depending on the specific month and scenario) to offset the appreciation pressure from other economic fundamentals. The fixed exchange rate target under scenario (a) has significant effects on the import price inflation rate

\footnotetext{
${ }^{3}$ The foreign exchange intervention decision in Japan is made by the Ministry of Finance, while the interventions are implemented by the Bank of Japan.
} 
but negligible effects on the inflation rate of consumer price index (CPI). In particular, pegging the exchange rate could have helped Japan avoid a possible $-4 \%$ annualized deflation of import prices as suggested by the unconditional forecast. Moreover, targeting annualized import price inflation at $2 \%$ under scenario (b) has moderate effects on consumer price inflation rate and predicts that the yen would depreciate slightly at the beginning of 2018 .

This paper makes at least four contributions to the literature. First, our paper is the first paper to estimate the shock-dependent ERPT with a narrative sign approach. We show that the identification strategy with only the traditional sign and zero restrictions may provide a misleading picture of the shock-dependent ERPT ratio because it retains many draws of structural parameters that are inconsistent with the established narrative account of historical events. Second, we are also the first to show that previous studies in the shock-dependent ERPT literature have underestimated the importance of the exchange rate shock in the currency movement because the identification with only the traditional sign and zero restrictions may have confounded the exchange rate shock with the domestic demand shock. The narrative sign restrictions help distinguish them. Third, our paper makes a novel contribution to the literature by applying the structural scenario analysis of Antolin-Diaz et al. (2018) to forecast future prices conditional on certain exchange rate interventions. Previous studies have stressed the idea that policymakers should take into account what drives the exchange rate movements when forecasting the impact of currency movements on future prices (Shambaugh 2008 and Forbes et al. 2018a). We implement the idea in a scientific way. Last but not least, our paper contributes to the empirical evidence of the ERPT in Japan.

The rest of our paper is organized as follows. Section 2 sets out the basic SVAR framework, illustrates the estimation approach as well as the identification strategy, and describes the data used in estimation. Section 3 assesses the necessity of identifying the structural shocks with the narrative sign approach by comparing the identification scheme with and without narrative sign restrictions along three dimensions, including the impulse responses, the distribution of the exchange rate shocks, and the counterfactual analysis. Section 4 reports the central results of the ERPT ratios conditional on different structural shocks as well as the contribution of each shock to the endogenous variables. Section 5 studies the policy implications of the identified exchange rate shocks by forecasting future prices conditional on certain policy scenarios. Section 6 concludes.

\section{Empirical Methodology}

In this section, we first outline the SVAR model and our choice of prior distributions. We then discuss our identification strategies. Finally, we describe the data used in estimation.

\subsection{The Empirical Model}

Building on Forbes et al. (2018a), our starting point is an SVAR model of the form: 


$$
\mathbf{y}_{t}^{\prime} \mathbf{A}_{\mathbf{0}}=\sum_{i=1}^{6} \mathbf{y}_{t-i}^{\prime} \mathbf{A}_{i}+\mathbf{c}+\boldsymbol{\epsilon}_{t}^{\prime}, \quad 1 \leq t \leq T,
$$

where $\mathbf{y}_{t}$ consists of six endogenous variables measured at monthly frequency: Japanese real industrial production growth, Japanese consumer price inflation, the Bank of Japan policy rate, the percentage change in the nominal effective exchange rate of the yen (defined as foreign currency per unit of yen), Japanese import price inflation, and the percentage change in the foreign export price. The trend in the policy rate is removed with the linear projection approach of Hamilton (2018). ${ }^{4}$ The detrended policy rate can be interpreted as the interest rate gap which signifies the stance of monetary policy. We employ a lag length of six months following An and Wang (2012), Corbo et al. (2018) and Forbes et al. (2018a). $\mathbf{A}_{i}$ is a $6 \times 6$ coefficient matrix of parameters for $i=1,2, \ldots \ldots 6$, while $\mathbf{A}_{0}$ is an invertible impact matrix which defines the contemporaneous structural relationship among the endogenous variables. $\mathbf{c}$ is a $1 \times 6$ vector of constants, while $\boldsymbol{\epsilon}_{t}$ is a $6 \times 1$ vector of exogenous economic shocks with mean zero and an identity covariance matrix $\mathbf{I}_{6}$.

We follow Arias et al. (2018) and rewrite the SVAR model described in equation (1) compactly as

$$
\mathbf{y}_{t}^{\prime} \mathbf{A}_{0}=\mathbf{x}_{t}^{\prime} \mathbf{A}_{+}+\boldsymbol{\epsilon}_{t}^{\prime}, \quad 1 \leq t \leq T,
$$

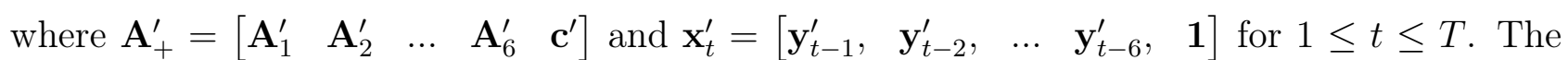
reduced-form VAR model implied by equation (2) can be expressed as

$$
\mathbf{y}_{t}^{\prime}=\mathbf{x}_{t}^{\prime} \mathbf{B}+\mathbf{u}_{t}^{\prime}, \quad 1 \leq t \leq T
$$

where the coefficient matrix $\mathbf{B}=\mathbf{A}_{+} \mathbf{A}_{0}^{-1}$, and $\mathbf{u}_{t}^{\prime}=\boldsymbol{\epsilon}_{t}^{\prime} \mathbf{A}_{0}^{-1}$ corresponds to a vector of reducedform regression disturbances with a covariance matrix $\boldsymbol{\Sigma}=\left(\mathbf{A}_{0} \mathbf{A}_{0}^{\prime}\right)^{-1}$. The distribution of the reduced-form parameters $(\mathbf{B}, \boldsymbol{\Sigma})$ can be inferred from the observables in the vector $\mathbf{y}_{t}$. The identification of the SVAR model of equation (2) amounts to searching a mapping from reduced-form parameters $\mathbf{B}$ and $\boldsymbol{\Sigma}$ to structural parameters $\mathbf{A}_{0}$ and $\mathbf{A}_{+}$.

We can uncover one such mapping by simply decomposing the covariance matrix, $\boldsymbol{\Sigma}$, so that $\mathbf{A}_{0}=h(\boldsymbol{\Sigma})^{-1}$ and $\mathbf{A}_{+}=\mathbf{B} h(\boldsymbol{\Sigma})^{-1}$, where $h(\boldsymbol{\Sigma})$ is any decomposition of the covariance matrix $\boldsymbol{\Sigma}$ satisfying $h(\boldsymbol{\Sigma})^{\prime} h(\boldsymbol{\Sigma})=\boldsymbol{\Sigma}$. Without loss of generality, we will take $h(\cdot)$ to be the Cholesky decomposition. Nevertheless, it is noted that the Cholesky decomposition is not the only mapping from the reduced-form parameters $(\mathbf{B}, \boldsymbol{\Sigma})$ to the structural parameters $\left(\mathbf{A}_{0}, \mathbf{A}_{+}\right)$. In fact, as argued by Arias et al. (2018), both sets of the structural parameters $\left(\mathbf{A}_{0}, \mathbf{A}_{+}\right)$ and $\left(\tilde{\mathbf{A}}_{0}, \tilde{\mathbf{A}}_{+}\right)$would be consistent with the same reduced-form parameters $(\mathbf{B}, \boldsymbol{\Sigma})$ and thus imply the same distribution of the process $\mathbf{y}_{t}$ (i.e., observationally equivalent) if and only if

\footnotetext{
${ }^{4}$ Forbes et al. (2018a) include similar variables in their model. However, they study the ERPT for the U.K. with quarterly data. Forbes et al. (2018a) detrend the interest rate series with the Hodrick-Prescott filter. However, Hamilton (2018) criticizes the use of the Hodrick-Prescott filter for various reasons. As such, we use the linear projection method to remove the trend in the interest rate instead. Wynne and Zhang (2018b) and Grossman et al. (2019) discuss how to estimate the trend in the interest rate with a more structural model.
} 
$\mathbf{A}_{0}=\tilde{\mathbf{A}}_{0} \mathbf{Q}$ and $\mathbf{A}_{+}=\tilde{\mathbf{A}}_{+} \mathbf{Q}$ for some orthogonal matrix $\mathbf{Q}$. The observational equivalence between $\left(\mathbf{A}_{0}, \mathbf{A}_{+}\right)$and $\left(\tilde{\mathbf{A}}_{0}, \tilde{\mathbf{A}}_{+}\right)$causes an identification problem. To overcome this problem, we need to impose additional restrictions to infer the distribution of the structural parameters.

In practice, the identification of the structural parameters $\left(\mathbf{A}_{0}, \mathbf{A}_{+}\right)$can be reduced to the inference on the joint distribution of $(\mathbf{B}, \boldsymbol{\Sigma}, \mathbf{Q})$. This is because there is an one-to-one mapping between the structural parameters $\left(\mathbf{A}_{0}, \mathbf{A}_{+}\right)$and the reduced form parameters $(\mathbf{B}, \boldsymbol{\Sigma}, \mathbf{Q})$, which can be defined as:

$$
f_{h}\left(\mathbf{A}_{0}, \mathbf{A}_{+}\right)=(\mathbf{B}, \boldsymbol{\Sigma}, \mathbf{Q})
$$

where $\mathbf{B}=\mathbf{A}_{+} \mathbf{A}_{0}^{-1}, \mathbf{\Sigma}=\left(\mathbf{A}_{0} \mathbf{A}_{0}^{\prime}\right)^{-1}$ and $\mathbf{Q}=h\left(\left(\mathbf{A}_{0} \mathbf{A}_{0}^{\prime}\right)^{-1}\right) \mathbf{A}_{0}$. It is straightforward to show that $h\left(\left(\mathbf{A}_{0} \mathbf{A}_{0}^{\prime}\right)^{-1}\right) \mathbf{A}_{0}$ is an orthogonal matrix and the function $f_{h}(\cdot)$ is invertible, with its inverse defined by:

$$
f_{h}^{-1}(\mathbf{B}, \boldsymbol{\Sigma}, \mathbf{Q}) \equiv\left(h(\boldsymbol{\Sigma})^{-1} \mathbf{Q}, \mathbf{B} h(\boldsymbol{\Sigma})^{-1} \mathbf{Q}\right),
$$

where $\mathbf{A}_{0}=h(\boldsymbol{\Sigma})^{-1} \mathbf{Q}$ and $\mathbf{A}_{+}=\mathbf{B} h(\boldsymbol{\Sigma})^{-1} \mathbf{Q}$.

We infer the joint distribution of the parameters $(\mathbf{B}, \boldsymbol{\Sigma}, \mathbf{Q})$ with the Bayesian approach. To let the data speak for itself, we adopt a non-informative conjugate uniform-normal-inverseWishart prior, as in Uhlig (2005), i.e., a normal prior for matrix B, an inverse-Wishart prior for matrix $\boldsymbol{\Sigma}$, and a uniform prior for $\mathbf{Q}$ over the set of all $6 \times 6$ matrices denoted as $\mathcal{O}(6){ }^{5}$

We impose a combination of short-run and long-run zero restrictions, traditional sign restrictions, and narrative sign restrictions to identify the structural shocks. We implement the estimation and identification strategy with an algorithm that combines the procedure developed in Arias et al. (2018) for traditional sign and zero restrictions with the approach introduced in Antolín-Díaz and Rubio-Ramírez (2018) for imposing narrative sign restrictions. The algorithm draws the reduced-form parameters, $(\mathbf{B}, \boldsymbol{\Sigma})$, from a normal-inverse-Wishart distribution, draws the orthogonal matrix, $\mathbf{Q}$, from a uniform distribution conditional on zero restrictions, and retains only the draws that satisfy the traditional and narrative sign restrictions. Note that the algorithm also includes two steps for importance sampling which resample the draws to ensure that the posterior draws of $(\mathbf{B}, \boldsymbol{\Sigma}, \mathbf{Q})$ are drawn independently from a uniform-normal-inverseWishart posterior distribution conditional on the zero restrictions, traditional and narrative sign restrictions. ${ }^{6}$ The algorithm is detailed in the Technical Appendix.

\footnotetext{
${ }^{5}$ Our results are robust when using the Minnesota prior, which indicates that the prior may play little role in the inference. The results are available upon request.

${ }^{6}$ With the change of variable theorems, Arias et al. (2018) shows that the posterior of the structural parameters, $\left(\mathbf{A}_{0}, \mathbf{A}_{+}\right)$, drawn in this way satisfy a normal-general-normal distribution. See Arias et al. (2018) for more details on the definition of the normal-generalized-normal distribution.
} 


\subsection{Identification Strategy}

\subsubsection{Traditional Sign and Zero Restrictions}

We employ a set of traditional sign and zero restrictions in addition to the narrative sign approach of Arias et al. (2018) to identify the full set of shocks, including an aggregate supply shock, an aggregate demand shock, a monetary policy shock, an exogenous exchange rate shock, a persistent foreign export price shock, and a transitory foreign export price shock. The traditional sign restrictions are imposed on the impulse responses of the endogenous variables to the structural shocks, while the narrative sign restrictions are imposed either on the sign of the shocks or the contribution of the structural shocks to the endogenous variables using historical decompositions. We extract the narrative information based on specific historical episodes to elicit the narrative sign restrictions, which narrows down the set of admissible structural models satisfying the traditional sign and zero restrictions.

Table 1 outlines the traditional sign and zero restrictions which broadly follow Forbes et al. (2018a) and reflects several relatively uncontroversial ideas. ${ }^{7}$ We deviate from Forbes et al. (2018a) in the identification of the two foreign shocks. Forbes et al. (2018a) identify a persistent and a transitory foreign output shock, rather than foreign export price shocks, by assuming that the transitory output shock has no long-run effects on the domestic output. However, without including a properly measured foreign output series in the endogenous vector, the transitory and persistent foreign output shocks are weakly identified. As shown in Forbes et al. (2018a), the impulse responses to foreign output shocks exhibit very wide confidence bands which may reflect the diverse sources and the lack of strict identifying criteria for these two output shocks. Thus, we follow the idea of Shambaugh (2008) and instead identify two alternative foreign shocks, i.e., the persistent and transitory foreign export price shock. ${ }^{8}$ The restrictions that we impose are based on three sets of assumptions.

[Table 1 about here.]

First, we assume that domestic shocks do not affect foreign export prices either on impact or in the long run. This is a standard small open-economy assumption that limits the influence of domestic shocks on the evolution of foreign export prices. This assumption is largely in line with Campa and Goldberg (2005) who take the foreign price level as a control variable when studying the ERPT to import prices with a univariate regression for 23 OECD countries including Japan. Shambaugh (2008), Forbes et al. (2018b) and Ha et al. (2019) also assume that Japan is a small open-economy when estimating its shock-dependent ERPT. In our SVAR model, we identify a transitory and a persistent foreign export price shock, both of which are allowed to affect the foreign export price immediately. However, only the persistent foreign export price shock can affect foreign export prices in the long run. The two foreign export price

\footnotetext{
${ }^{7}$ We use the approach introduced in Arias et al. (2018) to combine short-run zero, long-run zero, and traditional sign restrictions, which is arguably more scientific than the approach of Binning (2013) that Forbes et al. (2018a) have used. Arias et al. (2018) draw from the posterior distribution of structural parameters conditional on the sign and zero restrictions, which is a property that Binning (2013) method lacks.

${ }^{8}$ The view that world shocks are mostly transmitted by the relative prices between two countries is in line with the prediction of many conventional open economy real business-cycle models (Mendoza 1995; Kose 2002).
} 
shocks may correspond to various potential sources of the shock that may shift foreign export prices, such as a global productivity shock, a global oil price shock, or a global demand shock.

Second, we assume that only the domestic supply shock and the two foreign shocks may affect domestic output, proxied by the industrial production index, in the long run. The idea that the domestic supply shock is the only domestic shock that affects output in the long run is standard, which is in line with the restrictions used in Blanchard and Quah (1989) and Shambaugh (2008). Allowing both foreign export price shocks to affect domestic output in the long run is motivated by the idea that the rest of the world is of greater size than Japan, so the foreign shocks may affect Japan's domestic output level in the long run through international technological spillovers across countries, as explained in Kose et al. (2003), Rabanal et al. (2011) and Benhabib et al. (2014). ${ }^{9}$

Third, we impose sign restrictions on the impulse responses to the structural shocks which can be motivated by open-economy DSGE models like the ones adopted in Devereux and Yetman (2002) and Forbes et al. (2018a). In particular, positive supply shocks are restricted to have a negative impact on consumer prices but exert positive effects on domestic industrial production. Positive demand shocks are associated with a positive impact on industrial production and consumer prices. Consistent with Forbes et al. (2018a), we hypothesize that stronger domestic demand would induce a counter-cyclical tightening of monetary policy (i.e., an increase in the policy rate) to suppress possible demand-driven inflation and bring about an appreciation of the yen, as in Ellis et al. (2014). ${ }^{10}$ A positive monetary policy shock, implying a rise in the policy rate, is identified as having a contractionary real output effect, a deflationary effect on consumer prices, and inducing an appreciation of the nominal exchange rate on impact. Similar to An and Wang (2012), an exogenous exchange rate shock is assumed to lead to a drop in consumer prices and the policy rate when the yen appreciates. We impose the traditional sign restrictions only for the month that the shock occurs, which reflects the instantaneous direct effects of the structural shocks. We remain agnostic about how the identified structural shocks propagate in the subsequent periods and do not rule out that general equilibrium effects may lead to a sign reversal. As a result, no sign restrictions are imposed on the impulse responses beyond the impact period. However, we find that our impulse responses usually satisfy the imposed sign restrictions for subsequent periods.

We define positive foreign export price shocks as shocks which increase foreign export prices on impact. However, as in Forbes et al. (2018a), we do not impose any sign restrictions on the effects of the two foreign export price shocks on any other variables and only differentiate them by the long-run restriction imposed on the transitory foreign export price shock. In addition, we remain agnostic about how domestic import prices, the main variable of interest, react to different structural shocks. As a result, we impose no restrictions on the impulse responses of domestic import prices.

\footnotetext{
${ }^{9}$ The foreign export price shocks, either persistent or transitory, may incorporate shocks that have permanent effects on the world output such as global technology shocks, oil price shocks and global financial shocks. The effects are further transmitted to Japan through international trade and finance.

${ }^{10}$ When central bank raises the interest rate, hot money flows in to take advantage of the better rate of Japan, leading to yen appreciation. The appreciation of the yen will also help subdue the demand-driven inflationary pressure.
} 


\subsubsection{Narrative Sign Restrictions}

Forbes et al. (2018a) is one of the first attempts to study ERPT with a combination of traditional sign and zero restrictions for the U.K. A few other studies follow this strand of literature with somewhat different SVAR models and impose different combinations of zero and traditional sign restrictions (e.g., Comunale and Kunovac (2017) for the euro area, Corbo et al. (2018) for Sweden, and Forbes et al. (2018b) for 26 diverse economies). The advantage of the traditional sign restriction approach lies in the fact that it imposes minimalist restrictions which are generally weaker than other earlier identification approaches and are typically uncontroversial among most economists. However, as argued by Fry and Pagan (2011), Kilian and Murphy (2012) and Arias et al. (2018), the traditional sign restrictions imposed on impulse responses may retain a set of structural parameters with implausible implications and may be inconsistent with our interpretation of historical episodes. The impulse responses identified by the traditional sign restriction approach tend to have wide confidence bands, making it difficult to arrive at meaningful economic conclusions. Thus, Arias et al. (2018) develop a new identification approach, i.e., the narrative sign approach, which complements the traditional sign approach by imposing restrictions that constrain the structural shocks and/or historical decompositions during specific historical episodes. Arias et al. (2018) show that narrative sign restrictions are "highly informative", and sharpen and even change the inferences drawn from SVARs identified using traditional sign restrictions.

This paper contributes to the ERPT literature by identifying the exchange rate shock using narrative sign restrictions. Exchange rate shocks are defined as exchange rate fluctuations that cannot be explained by the economic fundamentals (Farrant and Peersman 2006). We single out the Plaza Accord to elicit the narrative sign restrictions for our exercise. The Plaza Accord was signed in late September of 1985, under which the U.S., the U.K., France, Germany, and Japan pledged concerted policy intervention to bring the dollar down. It is remembered as one of the most significant events in the history of international finance during the post-WWII era and is regarded as a major success. For Japan, the agreement was a pivotal event that triggered the epic yen gyrations and the long-run trend of yen appreciation over the next decade (Obstfeld 2009 and Ito 2015).

Figure 1 plots the monthly time series of the bilateral exchange rate between the yen and the dollar from 1980M1 to 2017M12 with the Plaza Accord episode marked as a vertical line. The interventions had obvious impacts on the exchange rate instantaneously. The Japanese yen appreciated against the dollar by $61 \%$ between September 1985 and September 1988. We consider that the exchange rate movements in the fall of 1985 were mostly caused by exogenous exchange rate shocks for the following reasons. First, the Plaza Accord was a policy initiative in the dollar foreign exchange market which signaled a shift from a "minimalist approach to intervention" to an "activist approach" of the U.S. foreign exchange policy (Bordo et al. 2015). Second, the success of these coordinated interventions was by no means obvious ex-ante. It makes sense to attribute the resulting change in the exchange rate to an exogenous shock with respect to Japan's economic policy and the macroeconomic determinants in Japan. Therefore, the Plaza Accord episode of 1985 can naturally be considered as a generally agreed upon

exogenous exchange rate shock for Japan (Green et al. 2015, Kilian and Zhou 2019, and Ito 
and Yabu 2020). Accordingly, we impose the following narrative sign restrictions:

Narrative Sign Restriction 1: The exchange rate shock during the Plaza Accord episode causes the U.S. dollar to depreciate against the Japanese yen in October 1985.

Narrative Sign Restriction 2: For October 1985, exchange rate shocks are the most important contributor to the movements in the yen exchange rate. The absolute value of the contribution of the exchange rate shock is larger than the absolute value of the contribution of any other structural shocks.

[Figure 1 about here.]

Although the Plaza Accord was announced on September 22, 1985, and the yen had appreciated at the end of September, we choose to impose the restrictions in October rather than September for several reasons: First, the yen started to appreciate on September 19, 1985, which was before the Plaza Accord. We consider this appreciation to be due to other shocks rather than the exchange rate shock associated with the Plaza Accord. Since the signaling effects of the Plaza Accord intervention were not immediate, there was a time lag for the market to respond to the intervention. Second, the nominal exchange rate of the yen in October was on an obvious and significant appreciation trajectory, indicating the effectiveness of the Plaza Accord interventions. The monthly average exchange rate of the yen against the dollar went from 236.53 yen per dollar in September 1985 to 214.68 yen per dollar in October 1985. Third, although the yen continued to appreciate in November, we prefer not to impose a restriction in November, as the appreciation might be partly caused by monetary effects (Takagi 2007), which cannot be viewed as an exogenous exchange rate shock. Note that the narrative sign restrictions we impose do not rule out influences from other shocks while stressing the role played by the exchange rate shock during the Plaza Accord episode. The two narrative sign restrictions together with the traditional sign and zero restrictions described in Subsection 2.2.1 complete our identification strategy.

\subsection{Data Description}

We estimate the SVAR model described in the previous section with monthly data for Japan and the rest of the world over the period from 1980M2 through 2017M12 as some series are included in first differences. ${ }^{11}$ The six series included in our benchmark specification are Japanese industrial production growth, Japanese CPI inflation, the Bank of Japan policy rate, the percentage change in the nominal effective exchange rate of the yen, Japanese import price inflation, and the percentage change in foreign export prices.

We use "Production of Total Industry in Japan" from the OECD's Main Economic Indicator database in Haver Analytics to measure the real output of Japan. The growth rate of production is in turn computed as log differences of industrial production and scaled by 100 to convert the data series into month-to-month percentage changes. Consumer prices and import prices are

\footnotetext{
${ }^{11}$ The data series from 1980M2 to $1980 \mathrm{M} 7$ are only used as explanatory variables when estimating our SVAR model.
} 
the focus of this paper. The CPI inflation rate is defined as the monthly log difference (scaled by 100) of the CPI for Japan from the International Financial Statistics database. Similarly, we calculate the import price inflation rate as the monthly log difference (scaled by 100) of the import price index for Japan from the G10 database. Both of these two price series are non-seasonally adjusted as reported but are seasonally adjusted by Haver Analytics.

The policy rate in Japan was stuck at the effective zero lower bound for an extended period since the mid-1990s. To account for the asset purchasing/quantitative easing undertaken by the Bank of Japan, we combine the monthly average of the BIS daily policy rate series before September 1998 with the monthly average of the shadow rate for Japan of Krippner (2013) after October 1998 when the official policy rate fell to $0.25 \%$ and the shadow rate first touched the zero lower bound. ${ }^{12}$ The shadow rate indicates how the short-term policy rate would have behaved if policymakers could have driven it negative and is directly comparable with the shortterm interest rate in normal times (Lombardi et al. 2018). We detrend the interest rate series to account for the downward trend observed in the policy rate series over our sample period, where the trend is in turn estimated using the linear projection method of Hamilton (2018). ${ }^{13}$ The deviation of the interest rate from its long-run trend can be interpreted as the interest rate gap which signifies shifts in the stance of monetary policy.

The foreign export price series is calculated as the geometric weighted average of the foreign export prices of Japan's twenty-five major trade partners using the weights based on the value of the goods that Japan has imported. ${ }^{14}$ The twenty-five economies together account for over $75 \%$ of the total value of imports of Japan for most of our sample period. Similarly, the exchange rate series is constructed as the geometric weighted average of the bilateral exchange rates between the Japanese yen and the currencies of the same twenty-five countries (regions) using import weights. The nominal effective exchange rate is defined as foreign currency per unit of yen so that an increase implies an appreciation of the Japanese yen. To facilitate the replication of our results, we list the sources of all our data series, explain how we construct the effective indices, and plot all the data series used in the estimation in Appendix B.

\section{Assessing the Importance of Narrative Sign Restrictions}

We estimate the model with Bayesian methods. We make 212,160,000 attempts in drawing from the joint posterior distribution of $(\mathbf{B}, \mathbf{\Sigma}, \mathbf{Q})$ to obtain 10,000 acceptances satisfying the traditional sign and zero restrictions. Of the 10,000 accepted draws, 1,491 independent draws satisfy the narrative sign restrictions, which we consider sufficient to describe the posterior

\footnotetext{
${ }^{12}$ More detailed surveys of the monetary history in Japan can be found in Dell'Ariccia et al. (2018) and Wynne and Zhang (2018a) among others.

${ }^{13}$ Standard unit root tests indicate that the level of the policy rate is not stationary, but the detrended level is stationary.

${ }^{14}$ We select twenty-five important trade partners of Japan from 187 countries based on import goods value data from the International Monetary Funds Directions of Trade Statistics. The countries (regions) that we include are: Australia, Canada, China, Denmark, Finland, France Germany, Hong Kong, Indonesia, Ireland, Italy, Korea, Malaysia, Mexico, Netherlands, Philippines, Singapore, South Africa, Spain, Sweden, Switzerland, Taiwan (Province of China), Thailand, the U.K. and the U.S.
} 
distribution of the structural parameters and thus the impulse responses. Before showing the key results of shock-dependent ERPT, it is worth showing how the narrative sign restrictions can complement the traditional identification schemes in identifying structural shocks. We do this in three ways. First, we examine if the estimated impulse response functions agree with economic theory and our model. Second, we plot the exchange rate shock distribution to check if they are aligned with certain historical periods. Third, we lay out the counterfactual exchange rate path if only a specific shock occurred for certain periods.

\subsection{Impulse Responses}

Figures 2 and 3 display impulse responses of the six endogenous variables to one standard deviation of the structural shocks for up to 60 months. The blue solid lines and gray shaded area represent the median impulse responses along with confidence bands at the $68 \%$ threshold using only the traditional sign and zero restrictions listed in Table 1 . In the rest of the paper, we will refer to this method as the traditional identification method and the shocks identified by the traditional method as the traditional shocks. The red shaded area and solid lines display the equivalent quantities when Narrative Sign Restrictions 1-2 are also used. By comparing the red areas with the gray areas, the narrative sign restrictions are seen to be informative in the identification of the supply shock, the demand shock, and the exchange rate shock in substantially sharpening and even shifting the inferences originally identified with the traditional identification method. However, they have little influence over the impulse responses to the monetary policy shock, the persistent export price shock, and the transitory export price shock.

[Figures 2 and 3 about here.]

A positive supply shock identified with narrative sign restrictions causes a more persistent decrease in consumer prices. Different from the traditional approach, the supply shock identified with narrative sign restrictions induces a decline in the nominal interest rate. We deem the decrease of the policy rate more reasonable in the case of Japan since the Bank of Japan is focused on inflation and has been trying to escape the deflationary trap for the past two decades. The decrease in the interest rate further explains why the nominal exchange rate depreciates - rather than appreciates - in response to the positive supply shock. Similar to Forbes et al. (2018b), the effects of domestic supply shocks on import prices are small and insignificant. A positive demand shock, as expected, leads to an increase in output, consumer prices, the interest rate and the exchange rate of the yen. The appreciation of the yen passes through to import prices and causes a decrease in import prices.

The narrative sign restrictions can identify the exchange rate shocks more sharply by efficiently reducing the uncertainty of many impulse responses even we only impose the narrative sign restrictions based on a single event in a single month. The exchange rate shock identified by the narrative sign approach is of greater size, which increases the exchange rate by $2 \%$ in terms of the posterior median impulse response. This is approximately two times the corresponding responses by the exchange rate shock identified with the traditional sign and zero restrictions. Nevertheless, the impulse response of consumer prices to the narrative identified 
exchange rate shock is smaller. The immediate response of import prices to the narrative exchange rate shock is similar to the respective response of the traditionally identified exchange rate shock plotted in blue lines, while in the long run, import prices drop to a lower level in response to the narrative sign identified exchange rate shock. The above evidence suggests a less complete ERPT to both prices conditional on the exchange rate shock when imposing the narrative sign restrictions. This will be illustrated in more detail in Section 4.

Consistent with many other studies in the monetary SVAR literature, a positive monetary policy shock leads to a decrease in industrial production and consumer prices which at the same time strengthens the yen significantly and thus lowers import prices for a short period. A permanent rise in foreign export prices reflects a stronger demand from the rest of the world, which boosts domestic output, consumer prices, and import prices, while it strengthens the domestic currency. A temporary foreign export price shock, on the other hand, only increases foreign export prices for around one year and has an insignificant effect on the exchange rate. This may reflect the diverse factors that may lead to a transitory fluctuation in foreign export prices, such as global oil price shocks, financial shocks, risk shocks, and even foreign monetary policy shocks. Nevertheless, the transitory export price shock worsens the domestic terms of trade, which leads to a decline in domestic output and a less pronounced drop in consumer prices and import prices.

\subsection{Exchange Rate Shock Distribution and Counterfactual Analysis}

To explore further how the narrative sign restrictions assist in the identification of the exchange rate shock, we plot in Figure 4 the exchange rate shock distributions in the left panels and counterfactual exchange rate paths in the right panels around October 1985, July 1989, and March 2004. The gray histograms in the left panels plot the posterior distribution of the exchange rate shocks using the traditional identification specifications, while the red histograms plot the same distribution after incorporating the narrative sign restrictions. In the right panels, the solid thick lines indicate the actual exchange rate movements. The solid blue lines and the gray shaded areas correspond to the median and the $68 \%$ credible sets of the counterfactual exchange rate path if no structural shocks other than the exchange rate shock had occurred when shocks are identified with the traditional method. The solid red thin lines and red shaded areas plot the same results using the narrative sign restrictions.

We select October 1985, the Plaza Accord episode, since we impose the narrative sign restrictions directly on this month. We also examine two other periods of July 1989 and March 2004 based on the historical record of interventions. Note that we do not directly impose any narrative sign restrictions for the latter two periods. We will explore to what extent the narrative information of the Plaza Accord episode affects the inference of the shock distribution and the counterfactual analysis. This will help validate the shock identification. We consider July 1989 since the U.S. conducted about $\$ 22$ billion of combined intervention against the German mark and the Japanese yen around that time, which surpassed all interventions during the prior four years. Specifically, the U.S. bought $\$ 10.925$ billion equivalent of the yen cumulatively in 1989 (Belongia 1992). Given the unprecedented intervention by the U.S., much

of the variation in the exchange rate should be attributable to an appreciation shock of the 
yen in this episode. The episode of March 2004 was at the end of the Great Intervention Period (January 2003 to March 2004) of Japan's history when the monetary authority in Japan intervened in the foreign exchange market heavily to depreciate the yen. During the 15-month period, the size of the interventions amounted to 7\% of Japan's GDP and exceeded the total amount of interventions during the previous 11-year period. Furthermore, macroeconomic fundamentals had improved during the previous 15 months, and the economy was making a strong recovery in the first quarter of 2004. As noted in Ito (2005), interventions were relatively independent of economic developments in the first quarter of 2004. As such, it is interesting to explore how such interventions have shifted the distribution of the exchange rate shock and further contributed to the exchange rate dynamics.

[Figure 4 about here.]

For October 1985, Figure 4 shows that the exchange rate shock identified by the traditional approach is almost evenly distributed around zero. This implies that the traditional identification approach is uncertain about whether the exogenous exchange rate shock was an appreciation shock or a depreciation shock during that month. Similarly, the counterfactual analysis shows that the traditional exchange rate shock was rather unimportant in explaining the unexpected changes in the exchange rate observed in the same period. ${ }^{15}$ Many accepted draws even suggest that the exchange rate shock depreciated the yen in October 1985. This means that the set of admissible structural parameters implied by the traditional identification retains many structural parameters that go against the widely shared view that the exchange rate shock in the Plaza Accord period greatly appreciates the yen. By contrast, the narrative sign restrictions specification implies unanimously positive exchange rate shocks which appreciate the yen by $1 \%$ to $3.5 \%$. After imposing the narrative sign restrictions for only October 1985 , the exchange rate shock becomes the overwhelming contributor to the unexpected movements of the exchange rates for the Plaza Accord episode as shown by the counterfactual analysis, which is consistent with what happened. The reported results highlight the fact that the narrative information embedded in even a single event can shrink the set of admissible structural parameters so dramatically that the economic implications change.

We do not impose narrative sign restrictions for any periods other than October 1985. However, we find that the narrative sign restrictions may change our views on the distributions and historical contribution of the exchange rate shocks for other periods. The KolmogorovSmirnov test shows that there are significant differences between the distribution of the exchange rate shocks identified by the traditional approach and the same shocks identified by the narrative sign approach for all the three selected periods, with p-values close to 0. For July 1989, after imposing the narrative sign restrictions, the shock distribution is more skewed to the positive side compared to the traditional specification, which concurs with the fact that the interventions were intended to appreciate the yen. It is worth mentioning that the shock distribution for July 1989 renders special support to our identification strategy. The yen depreciated by $0.7 \%$ against the dollar in that month despite the large purchase of the yen by the Fed. Traditional

\footnotetext{
${ }^{15}$ In fact, the demand shock picked up a larger share of the exchange rate fluctuations in October 1985. The counterfactual analysis for other shocks is available upon request.
} 
identification methods cannot detect the positive shocks very well given the fall of the yen, while the narrative sign approach plots the distributions of shocks to be more consistent with the facts. ${ }^{16}$

For March 2004, the interventions were intended to make the yen depreciate. Again, the traditional specification indicates that the negative and positive shocks were distributed with similar posterior probability for that period, while the narrative sign restriction specification implies dominant depreciation shocks. The results from the narrative sign method are more consistent with the reality since the Bank of Japan sold 14.8 trillion yen over a 47-day period to make the yen depreciate (Ito 2005). While we impose narrative sign restrictions for only October 1985, the shock distributions for other periods better reflect the reality compared to the traditional identification specification. This indicates that the narrative information does help identify the exchange rate shocks. The counterfactual analysis also shows that the exchange rate shocks identified by the traditional strategy contribute much less to the exchange rate movements in 1987 and 2004 than their counterparts identified by the narrative sign approach. In sum, if one agrees with the assumption that the exchange rate shock was both positive and the most important contributor to the yen appreciation in October 1985, one should conclude that the exchange rate shocks are reasonably identified and the estimates of the shock-contingent pass-through can be plausibly estimated with the narrative sign approach.

\section{Exchange Rate Pass-Through}

A thorough understanding of ERPT and how ERPT may vary conditional on the nature of the shocks hitting the economy is of substantial importance for Japan for several reasons. First, the degree and timing of ERPT are important for interpreting the inflation dynamics of the economy, which is relevant for meeting the inflation target and the design of the monetary policy. For example, an exchange rate appreciation resulting from an exogenous exchange rate shock exerts downward pressure on consumer prices, in which case an inflation-targeting central bank, like the Bank of Japan, should loosen the monetary policy to counter the impact. If, in another scenario, a positive supply shock hits the economy, and the exchange rate depreciates in response to the positive supply shock, the downward pressure on the CPI due to the positive supply shock will be offset by upward pressure exerted by the exchange rate depreciation. The net effect on inflation is less clear. Second, the degree and timing of ERPT affect the strength of the expenditure-switching effect, which is important for the prospective adjustment of the country's external balances. According to Obstfeld (2002), high ERPT to import prices and low ERPT to consumer prices are required for a strong expenditure-switching effect. If the pass-through to aggregate prices is low, the quantity of imports would be reduced by only a small amount even for a large depreciation of the currency, thus limiting adjustment in real net exports. Third, knowledge of the ERPT to prices conditional on different shocks is crucial to understanding the period of deflation that coincided with the depreciation of the yen, like the ones we observed in 2000-2002 and 2004-2005. Using the "rule-of-thumb" prior would

\footnotetext{
${ }^{16}$ The yen depreciated by $16 \%$ against the dollar in the year of 1989. The intervention, to some extent, has slowed down the depreciation of the yen in July.
} 
imply incomplete yet positive pass-through from the exchange rate to prices, which is at odds with the observation of simultaneous deflation and depreciation. Studying shock-contingent ERPT allows us to make more specific statements about the ERPT in different circumstances conditional on the shocks.

The shock-dependent ERPT ratios are calculated based on the posterior distribution of the impulse responses. The pass-through coefficient for a period $t+\tau$ conditional on shock $\epsilon_{t}^{s}$ is calculated as follows:

$$
P T_{n, s}^{\tau}=\frac{\sum_{j=0}^{\tau} \partial \pi_{t+j} / \partial \epsilon_{t}^{s}}{\sum_{j=0}^{\tau} \partial \Delta e_{t+j} / \partial \epsilon_{t}^{s}},
$$

where $\pi_{t}$ can be either the rate of change of import prices or consumer prices, and $\Delta e_{t}$ denotes the growth rate of the nominal effective exchange rate. This is to say, the pass-through ratio gauges the change in accumulated inflation up to period $t+\tau$ following an exogenous structural shock, $\epsilon_{t}^{s}$, in period $t$, relative to accumulated changes between $t$ and $t+\tau$ of the exchange rate in response to the same structural shock.

We evaluate ERPT along two dimensions. On the one hand, we are interested in understanding how ERPT to consumer prices and import prices may depend on the nature of the shocks hitting the economy. On the other hand, we attempt to show how the narrative sign restrictions would update our inference of ERPT by comparing the ERPT ratios implied by the identification schemes with and without the narrative sign restrictions.

\subsection{Exchange Rate Pass-Through to Import Prices}

Figure 5 displays the ERPT ratios to import prices for horizons from 0 to 60 months after a shock. The upper panels show the median of the ratios, defined as the cumulative impulse responses of import prices relative to the exchange rate, conditional on each of the six structural shocks. The ERPT ratios conditional on shocks identified by the traditional identification scheme are plotted in the upper left panel and the corresponding ratios implied by the narrative sign approach are depicted in the upper right panel. The lower panels display the median ERPT ratio (solid lines) and the associated 68\% confidence bands (dashed lines) to the exogenous exchange rate shock. Note that the ERPT ratios under both identification schemes become practically constant from the 15-month horizon on, indicating that exchange rate movements have fully passed through to import prices after around one year.

[Figure 5 about here.]

Apart from the persistent foreign export price shock, the ERPT ratios for the other five shocks are all negative, which reasonably implies that an appreciation of the yen leads to a decrease in import prices. For the persistent foreign export price shock, its direct positive effects on import prices outweigh the dampening effects induced by the exchange rate appreciation. This leads to a positive ERPT ratio conditional on a persistent foreign export price shock. Similar to Forbes et al. (2018a), the ERPT ratio is shock-dependent and exhibits an appreciable amount of variation across shocks for both traditional and narrative sign identification 
schemes. Under both schemes, the ERPT is small conditional on the domestic supply shock and large conditional on the domestic demand shock. The pass-through ratios conditional on the exchange rate shock, the domestic monetary policy shock and the transitory foreign export price shock are of similar magnitude. The weak effects of a supply shock are intuitive: on the one hand, a positive supply shock alone will have dampening effects on import prices through the domestically-produced competing goods; on the other hand, a positive supply shock causes exchange rate depreciation, which has inflationary effects on import prices, so the two forces counteract each other and the resulting pass-through is low. ${ }^{17}$

The demand shock has a larger pass-through than the exogenous exchange rate shock, contradicting the evidence for the U.K. studied in Forbes et al. (2018a). There are two possible reasons. First, according to Leduc and Liu (2016), an uncertainty shock is a type of aggregate demand shock. When Japan experiences positive demand shocks caused by less uncertainty, the cost of borrowing decreases, which lowers the marginal cost of domestic producers significantly. Since some imports compete with domestically-produced goods, import prices will decrease, leading to a higher ERPT ratio. Second, Japan has historically implemented formal protectionist measures such as tariffs and quotas. Japanese imports are also discouraged by unofficial practices, such as the strong relationships ("invisible handshakes") between local suppliers and buyers, "just-in-time" inventory practices that give nearby suppliers an edge, and an unusually complex distribution system that creates substantial entry barriers for newcomers (Lawrence and Krugman 1987). In addition, Japanese firms have lower profit margins than U.S. and European companies, which are $6.1 \%$ versus $12 \%$ and 8.7\%, respectively in 2019 (Thomson Reuters). To compete in this harsh environment, importers are less likely to maintain profit margins when facing high demand shocks, as explained in Forbes et al. (2018a). They may even lower profit margins to capture market share from local companies. This explains why demand shocks are associated with higher pass-through.

The ERPT conditional on a purely exogenous exchange rate shock is usually of special interest to economists (see e.g., Donayre and Panovska 2016, Rincon and Rodríguez-Niño 2018 and Bonadio et al. 2019). We show in the lower panels of Figure 5 that the narrative sign restrictions are informative which sharpens the inferences on the rate of ERPT to import prices. For instance, the corresponding $68 \%$ confidence band of the long-run ERPT ratio narrows substantially from $[-0.18,-1.87]$ to $[-0.55,-1.05]$ by incorporating the narrative sign restrictions. The narrative sign restrictions also change the estimated magnitude of the ERPT ratio originally identified via traditional identification schemes. The posterior median of the ERPT ratio conditional on the traditional exchange rate shock is about -0.85 in the short run which converges to -0.97 after five years, suggesting a nearly complete pass-through in the long run. When imposing the narrative sign restrictions, the posterior median of the same ERPT ratio becomes lower in terms of the absolute values, shifting from -0.62 in the short run to -0.82 in the long run. Thus, the narrative sign approach suggests a less complete pass-through

\footnotetext{
${ }^{17}$ Many economists argue that a positive supply shock should strengthen the domestic currency since it raises the demand for the yen. The impulse responses in this paper suggest the opposite. As explained in the previous section, a positive supply shock lowers the price level which further results in a looser monetary policy and an increase in the supply of the yen. If the fear of deflation leads to an aggressive response of monetary policy as in Japan, the rising supply of the domestic currency should weaken, rather than strengthen, the yen.
} 
in the long run than the traditional approach. Gopinath et al. (2010) show that the shortrun ERPT depends on the share of imported goods invoiced in the local currency especially when prices are sticky. In particular, Burstein and Gopinath (2014) demonstrate with an openeconomy general equilibrium model that the upper bound for the short-run ERPT ratio is (1-share of local currency pricing) if foreign exporting firms do not raise their prices following an exogenous appreciation of the foreign currency. ${ }^{18}$ As reported in Gopinath (2015), around $23 \%$ of Japan's imported goods are priced in the local currency. Given that the absolute value of the short-run ERPT rate estimated by the narrative sign approach, 0.62 , is lower than the share of imported goods not invoiced in the local currency, 0.77, the narrative sign approach suggests that foreign exporting firms choose to lower their prices when the foreign currency appreciates. By contrast, the traditional approach suggests the opposite.

\subsection{Exchange Rate Pass-Through to Consumer Prices}

Figure 6 plots similar measures of ERPT ratios as shown in Figure 5 for import prices, but this time for consumer prices. A quick comparison between Figures 5 and 6 indicate that pass-through is less complete to consumer prices, and takes place with slower speed than to import prices. It takes more than two years for the ERPT ratios of consumer prices to converge to the long-run levels. Different from the conditional ERPT to import prices, domestic demand, domestic supply, and permanent export price shocks are found to result in positive pass-through coefficients to consumer prices as compared to the normal negative rule-of-thumb ERPT coefficients. The pass-through coefficient conditional on the demand shock is positive because a positive demand shock directly increases consumer price inflation, which dominates the dampening effects of currency appreciation caused by the positive demand shock. Similar arguments apply to the estimated positive ERPT ratio for the domestic supply shock. For a permanent export price shock, the direct and permanent positive effect on consumer prices through import prices outweighs the negative effect on consumer prices due to currency appreciation, leading to positive pass-through. So it is dangerous to always assume incomplete negative pass-through especially when simply regressing consumer prices against exchange rate series, given that the exchange rate is endogenous and some shocks may cause the simultaneous occurrence of deflation and depreciation.

[Figure 6 about here.]

The lower panels of Figure 6 show that the narrative information embedded in the single event of the Plaza Accord can dramatically shrink the confidence band for the ERPT ratio for exogenous exchange rate shocks compared with the traditional identification scheme,

\footnotetext{
${ }^{18}$ When firms do not adjust prices, the short-run ERPT to import prices is $100 \%$ for goods priced in the producers' currency while $0 \%$ for goods priced in the local currency. Thus, the aggregate ERPT will depend on the share of imports invoiced in the local currency. Under a Calvo price setting, Burstein and Gopinath (2014) show that the short-run ERPT equals $(1-V)+\kappa\left(V \Delta P^{L C P} / \Delta e+(1-V) \Delta P^{P C P} / \Delta e\right)$, where $V$ denotes the share of local currency pricing, $\kappa$ is the Calvo probability, $\left(\Delta P^{L C P} / \Delta e\right)$ measures how much local currency firms change their prices when exchange rate appreciates and $\left(\Delta P^{P C P} / \Delta e\right)$ is the counterpart for producer currency pricing firms. When foreign exporting firms lower their prices as foreign currency appreciates $\left(\Delta P^{P C P} / \Delta e \leqslant 0\right.$ and $\left.\Delta P^{L C P} / \Delta e \leqslant 0\right)$, the short-run ERPT cannot be greater than $(1-V)$.
} 
suggesting that the narrative sign identification is more efficient. On the one hand, the narrative sign restrictions reduce the $68 \%$ confidence band of the immediate ERPT ratio from $[-0.32,-0.02]$ to $[-0.01,-0.04]$, while the ERPT ratio confidence bands after five years shrink from $[-0.62,-0.07]$ to $[-0.15,-0.06]$. On the other hand, the narrative sign restrictions also lower the median of the ERPT ratio to consumer prices in terms of absolute values. With only the traditional sign and zero restrictions, the posterior median of the ERPT ratio from the exogenous exchange rate shock moves from -0.09 on impact to -0.20 after five years. By contrast, the corresponding ERPT implied by the narrative sign restrictions is much less complete which starts from -0.02 on impact and converges to -0.10 in the long run.

\subsection{Shock Contribution and the Time-Varying ERPT Ratio}

The above subsections show that the ERPT ratio may vary depending on what types of shocks drive the exchange rate movements. Recent work, such as Donayre and Panovska (2016), Moussa (2016) and Forbes et al. (2018b), documents that the ERPT ratios are time-varying in recent decades for many countries. Forbes et al. (2018a) argue that shock-dependent ERPT helps explain the time-varying ERPT because the shock decomposition of the exchange rate movements may evolve over time. Motivated by this idea, we first assess the contribution of the structural shocks by examining the forecast error variance decomposition and the historical decomposition from the SVAR model. Then, we analyze how the historical variation in the shock decomposition of the exchange rate can account for the time-varying ERPT documented in Donayre and Panovska (2016), Moussa (2016) and Forbes et al. (2018b). We attempt to answer the following questions: First, what shocks explain most of the variation in the exchange rate, import prices and other endogenous variables over our sample and for specific historical periods? Second, to what extent can the shock-dependent ERPT explain the variation of the ERPT over time? Third, how would the incorporation of the narrative sign restrictions improve the answers to the first two questions?

Tables 2 and 3 report the forecast error variance decomposition of the endogenous variables in our model contributed by the six structural shocks identified without and with narrative sign restrictions respectively. The two methods clearly contrast in the variance decomposition for the three key variables of the model (exchange rate, import prices, and consumer prices).

\section{[Tables 2 and 3 are about here.]}

First, the narrative-sign-identified exchange rate shock contributes more to the exchange rate movement than the counterpart identified by the traditional approach. Similar to Forbes et al. (2018b), Comunale and Kunovac (2017) and Corbo et al. (2018), we find that the traditional exchange rate shock only explains around $25 \%$ of the variation in the exchange rate over the horizons while other shocks, especially the supply shock and the demand shock, account for the majority of the variation. This sharply contrasts with the variance decomposition obtained using the narrative sign restrictions, in which the exogenous exchange rate shock accounts for $70 \%$ at the one-month horizon and $60 \%$ over the long run; the supply shock and the demand shock each account for around 10\%. The results under the narrative sign identification scheme are more consistent with the "exchange rate disconnect" puzzle documented in Meese and Rogoff 
(1983) which refers to the lack of correlation between exchange rates and other macro variables. In contrast to Forbes et al. (2018a), our results suggest that, while treating all exchange rate fluctuations as exogenous exchange rate shocks (as is common in the macro literature) is unlikely to completely capture the underlying dynamics, exogenous exchange rate shocks still deserve a special focus in analyzing ERPT ratios.

Second, the identification strategy with narrative sign restrictions implies a more pronounced contribution of the exchange rate shock to import prices, and a less significant role for the demand shock than the traditional identification method. Under the narrative sign identification framework, over $35 \%$ of the variance in import prices is attributable to the exchange rate shock, while only around $25 \%$ of the corresponding volatility is explained by the demand shock. By contrast, Table 2 shows that with the traditional identification approach, the demand shock is the most significant contributor to the movements of import prices, accounting for nearly $35 \%$ of the variation. The traditional exchange rate shock only accounts for $25 \%$ of the fluctuation of import prices.

Third, as opposed to import prices, movements in consumer prices are explained less by the narrative-sign-identified exchange rate shock than the same shock identified without the narrative sign restrictions. The traditional exchange rate shock explains more than $20 \%$ of the volatility in consumer prices compared to less than $7 \%$ of the corresponding contribution by the narrative-sign-identified exchange rate shock. At the same time, the narrative sign approach highlights the role of the demand shock in the movements of consumer prices. The demand shock contributes to more than $30 \%$ of the variation in consumer prices on impact, which is $10 \%$ more than the contribution of the exchange rate shock identified without the narrative sign restrictions. The contribution of other shocks exhibits less significant differences between the two identification strategies. This indicates that the traditional approach might have confounded the demand shock with the exchange rate shock. Without narrative sign restrictions, the traditional identification scheme is likely to overestimate the contribution of the exchange rate shock to consumer prices and tends to underestimate the significance of the exchange rate shock to import prices. The narrative sign restrictions have improved our understanding of what drives the movements in prices by accurately identifying the exchange rate shock.

We next plot the historical decomposition for year-to-year changes in the nominal effective exchange rate under both identification schemes in Figure 7 to better evaluate if the significance of the six shocks in determining the movements in the exchange rate has shifted over time. A quick glance at the historical decomposition confirms the difference in forecast error variance decomposition between the narrative sign approach and the traditional approach: the domestic supply shock and the domestic demand shock explain most of the variation in the exchange rate over the whole horizon under the traditional identification approach. However, the exchange rate shock itself accounts for a greater amount of the exchange rate movements than the other shocks when incorporating the information of narrative sign restrictions. In particular, the narrative-sign-identified exchange rate shock is responsible for the large appreciation of the yen in 1985, the reduced speed of appreciation in 1987, and the depreciation of the yen in 2011. All of these periods are accompanied by heavy and coordinated interventions by Japan and the U.S. Moreover, the large appreciation during the 2008-2010 crisis was associated with an 
estimated large exchange rate shock and domestic supply shock.

[Figure 7 about here.]

Figure 8 presents the historical decomposition of the year-to-year growth rate of import prices under both identification schemes. Import prices decline substantially around 1985, which is mostly attributable to the exchange rate shock identified with narrative sign restrictions. Import prices also drop dramatically during the global financial crisis from 2008 to 2010 due to the persistent and transitory global export price shocks. Import prices increase in 2017 which, similar to the exchange rate indices, is mostly due to the domestic demand and monetary shocks.

[Figure 8 about here.]

Figure 9 depicts the time-varying ERPT to the inflation rate of import prices and consumer prices in Japan, which is calculated as the weighted average of the shock-dependent ERPT ratios at the 1-year horizon based on the historical decomposition of the change in the exchange rate. ${ }^{19}$ The pass-through to import price inflation identified with the narrative sign approach, displayed in the blue solid line ("PT to IMP Narrative"), is rather volatile, which can be explained by the evolving composition of the shocks that contribute to the movements in the yen exchange rate. Consistent with Hara et al. (2015), we find that the pass-through to import prices has trended upward since 2008 after the global financial crisis. The pass-through to import prices also increases sharply in May 1984 and July 2005 when the demand shock, the shock with the highest ERPT, accounts for an increasing share of the exchange rate movement, as shown in Figure 7. By contrast, the pass-through to import prices plunges temporarily to its historically low level of -0.32 (in terms of the absolute value) in April 1992 when the persistent foreign export price shock, a shock with positive ERPT, accounts for over $27 \%$ of the variation in the exchange rate. The above results highlight the fact that the relationship between the exchange rate and import prices is time-varying, and can largely be explained by the changing distribution of shocks behind the exchange rate movements.

[Figure 9 about here.]

The time-varying ERPT to import prices identified with the traditional method ("PT to IMP Traditional") is less volatile than its narrative-sign-identified counterparts. This could be due to the different historical decompositions suggested by the two identification strategies as well as the fact that the shock-dependent ERPT identified by the narrative-sign approach exhibits more variation across shocks as shown in Figure 5. The two estimates of the timevarying ERPT deviate from one another substantially in some specific periods, such as in the

\footnotetext{
${ }^{19}$ As explained in Forbes et al. (2018a), this exercise leads to an estimate of the unadjusted (but shockdependent) time-varying ERPT, which does not control for movements in any other endogenous variables for each period. More specifically, although our model will control for the effects of each of our shocks in the SVAR model, it does not control for other events causing fluctuations in commodity prices and foreign export prices simultaneously.
} 
mid-1980s around the Plaza Accord period, 1992 when the asset price bubble bursts in Japan, and recent years after 2015. This highlights the merits of a proper identification strategy in evaluating the time-varying ERPT to import prices. The red lines plot the time-varying ERPT to consumer prices, where both lines fluctuate around zero. This is consistent with the reducedform estimates of -0.02 by Jiménez-Rodríguez and Morales-Zumaquero (2016). Nevertheless, this does not imply that the pass-through from exogenous exchange rate shock to consumer prices is insignificant. We show in the previous subsection of our paper that the ERPT to consumer prices conditional on the exchange rate shock is significantly different from 0 and converges to -0.10 in the long-run.

\section{$5 \quad$ Structural Scenario Analysis}

The above analysis shows that narrative sign restrictions are informative in sharpening the estimates of ERPT by improving the identification of the structural shocks. However, can the improved shock identification be useful in practical policy-making? This section attempts to study the policy implications of our exercise by implementing a structural scenario analysis of the sort proposed by Antolin-Diaz et al. (2018). The structural scenario analysis is essentially a forecasting exercise conditional on structural shocks, which highlights the necessity of correctly identifying the exchange rate shock. We attempt to investigate what would have been the forecast of the future import price and consumer price inflation rates under the following scenarios driven by the exchange rate shocks: (a) if the Ministry of Finance in Japan had fixed the exchange rate of the yen by unanticipated foreign exchange interventions; (b) if the Ministry of Finance in Japan had achieved a $2 \%$ import price inflation rate target by unanticipated foreign exchange interventions.

\subsection{Scenario (a): Fixed Exchange Rate}

In scenario (a), we assume that Japan intervened in the foreign exchange market to peg the value of the yen from January 2018 to June 2018. The upper panels of Figure 10 plots the median scenario forecast in blue under this scenario, with the $68 \%$ density forecast displayed in the shaded area. Our point forecast shows that the import price inflation rate would revert to approximately zero in the first quarter of 2018 while the month-to-month consumer price inflation rate would shift downward substantially. Without such an intervention, the median unconditional forecast, plotted in the central dotted lines, predicts that the month-to-month import price growth would persist at a level lower than $-0.33 \%$ for the next six months, implying an annualized import price inflation rate of $-4 \%$. The comparison between the structural scenario analysis and the unconditional forecast suggests that targeting a fixed exchange rate could have helped Japan avoid a deflation of import prices in 2018. Nevertheless, pegging the value of the yen would not have had a significant impact on consumer price inflation in 2018. In particular, the point forecast of the consumer price inflation rate under the scenario analysis is tantamount to the median of the unconditional forecast.

[Figure 10 about here.] 
Figure 10 also plots in the rightmost panel the probability density functions of the exchange rate shock implied by the structural scenario analysis. The gray shaded area outlines the contours of the standard normal distribution which is also the unconditional distribution of the structural shocks. Each of the dashed lines depicts the probability density functions of the prescribed exchange rate shocks needed to stabilize the exchange rate in the first half of 2018. The exchange rate shocks are tightly distributed around their posterior modes, which signifies the size of the unanticipated interventions to peg the value of the yen if the distributions of the other shocks remain the same as their historical distributions. The largest intervention is needed in March 2018, when the Ministry of Finance in Japan is obliged to intervene in the market to depreciate the yen by around 0.65 standard deviation, i.e., $1.3 \%$, to offset the appreciation pressure caused by other economic fundamentals. ${ }^{20}$ The interventions needed for other months are relatively moderate, which depreciate the yen by around $0.5 \%$ in April and June and less than 0.15\% in January, February, and May of 2018.

\subsection{Scenario (b): Stable Import Price Inflation}

An alternative scenario is when the Ministry of Finance targets a $2 \%$ annualized import price inflation. This scenario is of particular interest for the following reasons: First, the exchange rate shock identified by the narrative sign restrictions contributes a substantial amount of variation in import prices historically, and the degree of ERPT to import prices is high. This makes it feasible for stabilizing import price inflation with a reasonable size of foreign exchange interventions. Second, the Bank of Japan has specified a $2 \%$ inflation target but has failed to achieve it for many years. The Bank of Japan has argued that the movement of import prices was the most important reason contributing to the failure of inflation targeting; see Kawamoto et al. (2017). Our historical data also shows that the import prices of Japan have been rather volatile. Smets and Wouters (2002) show with an open-economy New Keynesian model the necessity of stabilizing import price inflation in making monetary policy when the degree of openness is high. Recent work, such as Matsumura (2018), illustrates with an open-economy model that Japan should target multiple price indices instead of a single CPI. ${ }^{21}$ Thus, in this section, we carry out a structural scenario analysis where Japan engages in unexpected foreign exchange interventions to peg the month-to-month import price growth at $0.17 \%$ from January 2018 to June 2018, i.e., a $2 \%$ annualized import price inflation rate.

The scenario analysis in the lower panel of Figure 10 shows that the yen would depreciate if Japan chooses to maintain stable import price inflation. This sharply contrasts with the significant appreciation of the yen if the forecast is exercised unconditionally. Both the scenario analysis and the unconditional forecast predict a steep decline in the month-to-month growth

\footnotetext{
${ }^{20} \mathrm{~A}$ standard deviation of the depreciation shock lowers the exchange rate growth by $2 \%$ as shown in the impulse response function section.

${ }^{21}$ The degree of pass-through from the exchange rate shock to CPI is low. If the central bank attempts to achieve the CPI inflation target, a tremendous amount of interventions are needed at the cost of other economic consequences as expressed in Betts and Devereux (1996) and Devereux and Engel (2002). Therefore, we follow the idea of Cavallino (2019) that foreign exchange interventions complement monetary policy and perceive that the central bank may employ foreign exchange interventions to stabilize import price inflation and at the same wield other monetary policy instruments to stabilize the CPI inflation rate.
} 
rate of the CPI, which falls from $0.30 \%$ to $-0.05 \%$ in January 2018 . However, the structural scenario analysis indicates that the median month-to-month consumer price growth rate would revert to $0.11 \%$ in March 2018, which is higher than the corresponding unconditional forecast of $0.06 \%$. This indicates that targeting a $2 \%$ annualized import price inflation rate would to some extent have helped Japan to achieve a higher consumer price inflation rate in 2018. The interventions required for a stable import price inflation target are moderate. According to the rightmost panel of Figure 10, the interventions to stabilize the annualized import price inflation rate at $2 \%$ should depreciate the yen by $0.26 \%$ for May 2018, $0.48 \%$ for February 2018, and around $0.88 \%$ for each of the other four months.

The structural scenario analyses studied in this section highlight the merits of properly identifying the exchange rate shock with the narrative sign approach. On the one hand, it helps forecast the evolution of future macroeconomic variables under certain scenarios. On the other hand, the identification of the exchange rate shock also provides more accurate information on the size of the interventions prescribed for particular policy objectives. We can easily extend these exercises to other scenarios driven by a mixture of the exchange rate shock and other shocks, such as scenarios with coordination between monetary policy and foreign exchange policy or foreign exchange interventions in the face of other shocks. Nevertheless, none of these meaningful exercises can be properly implemented without correctly identifying the exchange rate shock.

\section{Conclusion}

Following Forbes et al. (2018a), a burgeoning literature has emerged to estimate shock-dependent ERPT using SVAR models with shocks identified with a mixture of traditional sign and zero restrictions on impulse responses. While agreeing to the general idea that ERPT is shockdependent, we argue that the traditional sign and zero restrictions might distort the estimates of shock-dependent ERPT rates by retaining many draws that are inconsistent with the established narrative account of historical episodes. In this paper, we evaluate the shock-dependent ERPT to consumer and import prices in Japan with an alternative identification strategy. We complement the traditional sign and zero restrictions broadly following Forbes et al. (2018a) with the narrative sign restrictions related to the Plaza Accord. We find that the narrative sign restrictions are highly informative, and not only sharpen the identification of structural shocks but also change the inferences from an SVAR originally identified with only the traditional sign and zero restrictions. The exchange rate shock distributions and counterfactual paths align more closely with the historical record when the narrative sign restrictions are imposed, even for these periods when we do not impose any restrictions.

Our paper sheds some new light on the estimation of ERPT. On the one hand, we find significant variation in ERPT across different shocks in Japan. As a result, we should not estimate ERPT with a single-equation regression by assuming that the exchange rate is an exogenous variable. On the other hand, in contrast to recent papers on the shock-dependent ERPT, we show that the exchange rate shock identified by the narrative sign restrictions contributes the largest share of movements in the exchange rate. Thus, the exchange rate is more 
of a source of shocks than a shock absorber as in Farrant and Peersman (2006). We infer from the shock decomposition of endogenous variables that previous studies might underestimate the importance of the exchange rate shock because they have confounded the domestic demand shock with the exchange rate shock. The narrative sign restrictions help distinguish them. Thus, we should not downplay or even ignore the exchange rate shock when studying shockdependent ERPT as in Forbes et al. (2018b). Besides, the incorporation of the narrative sign restrictions lowers the posterior median estimates of the ERPT rates conditional on the exchange rate shock and shrinks substantially the confidence bands around the medians.

Finally, we carry out a novel structural scenario analysis along the lines of Arias et al. (2018) to show how our model can be applied to forecast prices conditional on certain foreign exchange interventions. Our results indicate that the knowledge of shock-dependent ERPT can shed light on the inflation dynamics in Japan and improve the ability to predict the impact of currency movements. The analysis in this paper can be easily applied to other countries. Our model can also be extended to study the effects of the exchange rate shock on commodity prices, capital flows, and other macroeconomic variables. In addition, we only incorporate the narrative sign information for a single event of the Plaza Accord. However, our model can be generalized to incorporate more narrative information for other events and for non-exchange-rate shocks. We leave these avenues open for future research. 


\section{Appendix A Bayesian Estimation of the SVAR Model}

The estimation and identification of our SVAR model can be easily implemented by combining the algorithm developed in Arias et al. (2018) for combining zero restrictions with traditional sign restrictions and the algorithm introduced in Antolín-Díaz and Rubio-Ramírez (2018) for combining traditional sign restrictions with narrative sign restrictions. The procedure consists of the following steps:

Algorithm 1 The following algorithm makes independent draws from the uniform-normalinverse-Wishart posterior of $(\mathbf{B}, \mathbf{\Sigma}, \mathbf{Q})$ conditional on the zero restrictions, traditional and narrative sign restrictions.

1. Draw $(\mathbf{B}, \mathbf{\Sigma})$ independently from the normal-inverse-Wishart posterior distribution as follows:

$$
p(\boldsymbol{\Sigma})=I W\left(T \mathbf{S}_{T}, T\right) \quad p(\operatorname{vec}(\mathbf{B}) \mid \boldsymbol{\Sigma})=N\left(\operatorname{vec}\left(\mathbf{B}_{T}\right), \boldsymbol{\Sigma} \otimes\left(\mathbf{X}^{\prime} \mathbf{X}\right)\right) I(\mathbf{B}),
$$

where $T$ is the sample size, $\mathbf{B}_{T}$ and $\mathbf{S}_{T}$ are, respectively, the ordinary least square estimates of the coefficient matrix and the covariance matrix, and $I(\mathbf{B})$ is an indicator function which equals to zero if the VAR is explosive and to one otherwise.

2. For $1 \leq j \leq 6$, draw $\mathbf{x}_{j} \in \mathbb{R}^{6+1-j-z_{j}}$ independently from a standard normal distribution and set $\mathbf{w}_{j}=\mathbf{x}_{j} /\left\|\mathbf{x}_{j}\right\|$, where $z_{j}$ is the number of zero restrictions imposed on the $j-t h$ shock.

3. Define $\mathbf{Q}=\left[\begin{array}{llll}\mathbf{q}_{1} & \mathbf{q}_{2} & \ldots & \mathbf{q}_{6}\end{array}\right]$ recursively by $\mathbf{q}_{j}=\mathbf{K}_{j} \mathbf{w}_{j}$ for any matrix $\mathbf{K}_{j}$ whose columns form an orthonormal basis for the null space of the $\left(j-1+z_{j}\right) \times n$ matrix defined as $\mathbf{M}_{j}=$

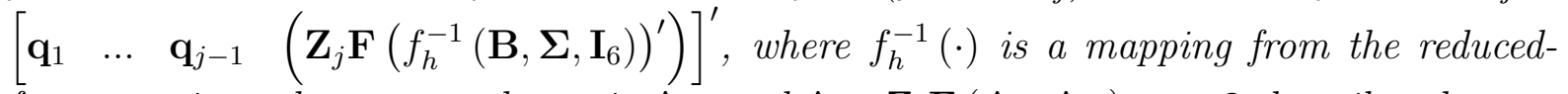
form matrix to the structural matrix $\mathbf{A}_{0}$, and $\mathbf{A}_{+}, \mathbf{Z}_{j} \mathbf{F}\left(\mathbf{A}_{0}, \mathbf{A}_{+}\right) \mathbf{e}_{j}=\mathbf{0}$ describes the zero restrictions imposed on shock $j$, and $\mathbf{e}_{j}$ is the selection vector with one in the $j$ - th place and zero elsewhere.

4. Calculate $\left(\mathbf{A}_{0}, \mathbf{A}_{+}\right)=f_{h}^{-1}(\mathbf{B}, \mathbf{\Sigma}, \mathbf{Q})$. If $\left(\mathbf{A}_{0}, \mathbf{A}_{+}\right)$satisfies the traditional sign restrictions., we keep the draw for further checks. In order to gurantee that the structural parameters are independent of each other conditional on the zero restrictions, we reweight the posterior draws with importance sampling with the weight set as detailed in Arias et al. (2018). 
5. Discard the draws that violate the narrative sign restriction and again reweight the draws with importance sampling to ensure that the posterior distribution of the reduced parameters is uniform-normal-inverse-Wishart. ${ }^{22}$ The importance weight is set with the approach in Antolin-Diaz and Rubio-Ramirez (2018), which involves simulating $M$ independent draws of structural shocks. We set $M=1000$ as suggested by Antolin-Díaz and RubioRamirez (2018) given that we only use one event to impose the narrative sign restriction.

6. Return to Step 1 until the required number of draws has been obtained.

\footnotetext{
${ }^{22}$ Without the importance weight step, we would be giving a higher posterior probability to draws that satisfy the narrative sign restrictions.
} 


\section{Appendix B Data Appendix}

Our data are from multiple sources. To facilitate replication of our results, we list in this appendix the sources of our data. The Haver mnemonics are listed when the data are from Haver Analytics.

Industrial Production: We use "Production of Total Industry in Japan" from the OECD's Main Economic Indicator database to measure the real output of Japan. The series is available at the FRED data bank (https://fred.stlouisfed.org/series/JPNPROINDMISMEI).

Consumer Prices: The CPI data are from Haver Analytics with the mnemonics sa(C158PC@IFS).

Import Prices: The import prices are from Haver Analytics with the mnemonics H158PFMI@G10.

Central Bank Policy Rate: We combine the monthly average of the BIS daily policy rate series before September 1998 ( https://www.bis.org/statistics/cbpol.htm) with the monthly average of the shadow rate for Japan of Krippner ( https: //www . rbnz.govt.nz/research-and-publications/research-programme/additionalresearch/measures-of-the-stance-of - united-states-monetary-policy/comparisonof-international-monetary-policy-measures) after October 1998.

Nominal Effective Exchange Rate: The nominal effective exchange rate is the geometric weighted average of the growth rates of the bilateral exchange rates between the yen and the currencies of twenty-five Japan's major trade partners using import weights from the IMF Direction of Trade Statistics. The bilateral exchange rates of the yen are calculated by dividing the bilateral exchange rate between the yen and the US dollar by the bilateral exchange rates between the currency of Japan's trade partners and the US dollar. The bilateral exchange rates of the US dollars are from Haver Analytics with the Haver mnemonics as follows. ${ }^{23}$

Australia: A193@FXRATES; Canada: FXCAUS@WEEKLY; China: A924@FXRATES; Denmark: $\quad$ FXDKUS@WEEKLY; Finland: $\quad$ FXFIUS@WEEKLY; France: FXFRUS@WEEKLY; Germany: FXDEUS@WEEKLY; Hong Kong: C532ECMA@IFS; Indonesia: C536ECMA@IFS; Ireland: C178ECMA@IFS; Italy: C136ECMA@IFS (prior to 99M1) and FXITUS@WEEKLY (post 99M1); Japan: FXJPUS@WEEKLY; Korea: C542ECMA@IFS; Malaysia: FXMYUS@WEEKLY; Mexico: C273ECMA@IFS; Netherlands: FXNLUS@WEEKLY; Philippines: A566@FXRATES; Singapore: C576ECMA@IFS; South Africa: A199@FXRATES; Spain: C184ECMA@IFS (prior to 99M1) and FXESUS@WEEKLY

\footnotetext{
${ }^{23}$ For Italy and Spain, we splice the exchange rates of their national currencies with the exchange rate of the Euro in 1999 according to the growth rate of the Euro.
} 
(post 99M1); Sweden: C144ECMA@IFS; Switzerland: FXCHUS@WEEKLY; Taiwan (Province of China): A528@FXRATES; Thailand: C578ECMA@IFS; the U.K.: FXGBUS@WEEKLY.

Effective Foreign Export Prices: Similar to the effective exchange rate, we compute the effective foreign export prices as the geometric weighted average of the export prices for the same twenty-five countries. The data sources for the export prices of each individual country are as follows. ${ }^{24}$

Australia: H193PFXI@G10; ${ }^{25}$ Canada: sa(C156CI@IFS) (prior to 97M1) and C156CP@IFS (post 97M1); China: China's External Trade Indices Monthly (in Chinese) from 93M1 to 04 M12 (SA by X13), H924PFXI@EMERGE after 05M1; ${ }^{26}$ Denmark: $12863 \ldots$ ZF... of IFS (prior to 95M1) and H128PFXI@G10 (post 95M1); Finland: sa(C172CP@IFS); France: 13264...ZF...(piror to 99M1) and H132PFXI@G10 (post 99M1); Germany: S134PFXI@G10; Hong Kong: C532CI@IFS; Indonesia: 53663...ZF... of IFS (prior to 98M1) and H536PFXI@EMERGEPR (after 98M1); Ireland: H178PFXI@G10; Italy: sa(C136CI@IFS); Korea: sa(N542PDXI@EMERGEPR); Malaysia: $\quad$ sa(C548CI@IFS) (prior to 87M12), 54863...ZF... of IFS (88M1 to 09M12) and H548IUX@EMERGEPR (post 10M1); Mexico: H273PX@EMERGELA; Netherlands: sa(C138CI@IFS); Philippines: H566PFXI@EMERGE; Singapore: sa(C576CP@IFS); South Africa: S199PFXI@EMERGE; Spain: H184PFXI@G10; Sweden: sa(C144CP@IFS); Switzerland: 14663...ZF... of IFS (prior to 10M11) and H146PFXI@G10 (post 10M11); Taiwan, Province of China: H528PFXI@EMERGE (prior to 81M10) and the Directorate General of Budget, Accounting and Statistics (post 81M10); Thailand: H578PFXI@EMERGEPR; the U.K.: sa(C112CP@IFS); the U.S.: sa(C111CP@IFS).

As discussed in the paper, we follow Forbes et al. (2018) and include the following series as the endogenous variables of our vector autoregression model: Japanese real industrial production growth, Japanese consumer price inflation, the detrended Bank of Japan policy rate, the percentage change in the nominal effective exchange rate of the yen (defined as foreign currency per unit of yen), Japanese import price inflation, and the percentage change in the foreign export price. The six series are plotted below.

\footnotetext{
${ }^{24}$ When the foreign export prices are in the US dollar, we convert them into their national currency with the corresponding exchange rate.

${ }^{25}$ The original data is quarterly for Australia, Philippines, South Africa, and Taiwan, Province of China (prior to 81M10). We interpolate data using the cubic spline method, see more details at https://columbiaeconomics.com/2010/01/20/how-economists-convert-quarterly-data-intomonthly-cubic-spline-interpolation/.

${ }^{26}$ Imports from China account for less than 5\% of Japan's total imports before 1993. We drop China when calculating the effective exchange rate and the effective export prices for the period before 1993 .
} 


\section{Figure B.1: Data Series}
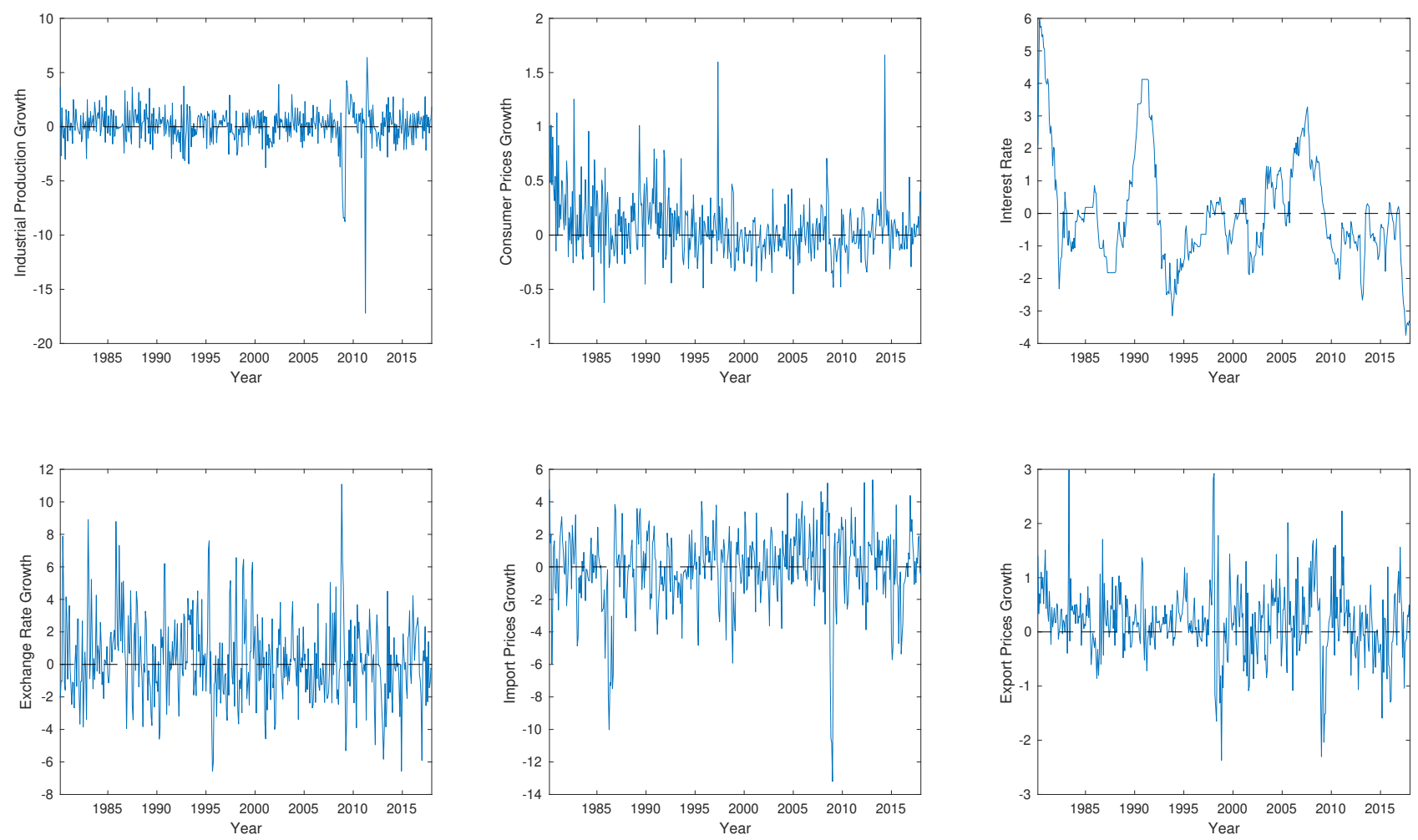

Notes: The figure plots the six series used to estimate the vector autoregression model. The series are from 1980M2 to 2017M12. 


\section{References}

Adolfson, M. (2001). Monetary policy with incomplete exchange rate pass-through. Sveriges Riksbank Working Paper Series No. 127.

An, L. and J. Wang (2012). Exchange rate pass-through: Evidence based on vector autoregression with sign restrictions. Open Economies Review 23(2), 359-380.

Antolin-Diaz, J., I. Petrella, and J. Rubio Ramírez (2018). Structural scenario analysis with SVARs. CEPR Discussion Paper No. DP12579.

Antolín-Díaz, J. and J. F. Rubio-Ramírez (2018). Narrative sign restrictions for SVARs. American Economic Review 108(10), 2802-2829.

Arias, J. E., J. F. Rubio-Ramírez, and D. F. Waggoner (2018). Inference based on structural vector autoregressions identified with sign and zero restrictions: Theory and applications. Econometrica 86(2), 685-720.

Baumeister, C. and J. D. Hamilton (2019). Structural interpretation of vector autoregressions with incomplete identification: Revisiting the role of oil supply and demand shocks. American Economic Review 109(5), 1873-1910.

Belongia, M. T. (1992). Foreign exchange intervention by the United States: A review and assessment of 1985-89. Federal Reserve Bank of St. Louis Review 74, 32-51.

Benhabib, J., J. Perla, and C. Tonetti (2014). Catch-up and fall-back through innovation and imitation. Journal of Economic Growth 19(1), 1-35.

Betts, C. and M. B. Devereux (1996). The exchange rate in a model of pricing-to-market. European Economic Review 40(3-5), 1007-1021.

Betts, C. and M. B. Devereux (2000). Exchange rate dynamics in a model of pricing-to-market. Journal of International Economics 50(1), 215-244.

Binning, A. (2013). Underidentified SVAR models: A framework for combining short and long-run restrictions with sign-restrictions. Norges Bank Working Papers No. 2013-14.

Blanchard, O. J. and D. Quah (1989). The dynamic effects of aggregate demand and supply disturbances. The American Economic Review 79(4), 655-673.

Bonadio, B., A. M. Fischer, and P. Sauré (2019). The speed of exchange rate pass-through. Journal of the European Economic Association.

Bordo, M. D., O. F. Humpage, and A. J. Schwartz (2015). US foreign-exchange-market intervention during the Volcker-Greenspan era, 1981-1997. In Strained Relations: US ForeignExchange Operations and Monetary Policy in the Twentieth Century, pp. 268-331. University of Chicago Press. 
Borensztein, E. and V. Queijo Von Heideken (2016). Exchange rate pass-through in South America: An overview. IDB Working Paper Series No. IDB-WP-710.

Burstein, A. and G. Gopinath (2014). International prices and exchange rates. In Handbook of International Economics, Volume 4, pp. 391-451. Elsevier.

Campa, J. M. and L. S. Goldberg (2005). Exchange rate pass-through into import prices. Review of Economics and Statistics 87(4), 679-690.

Cavallino, P. (2019). Capital flows and foreign exchange intervention. American Economic Journal: Macroeconomics 11(2), 127-170.

Comunale, M. (2019). An investigation of the exchange rate pass-through in the Baltic states. Bank of Lithuania Discussion Paper Series, No. 13/2019.

Comunale, M. and D. Kunovac (2017). Exchange rate pass-through in the euro area. European Central Bank Working Papers No. 2013-14.

Corbo, V., P. Di Casola, et al. (2018). Conditional exchange rate pass-through: Evidence from Sweden. Sveriges Riksbank Working Paper No. 352.

Corsetti, G., L. Dedola, and S. Leduc (2008). High exchange-rate volatility and low passthrough. Journal of Monetary Economics 55(6), 1113-1128.

Dell'Ariccia, G., P. Rabanal, and D. Sandri (2018). Unconventional monetary policies in the Euro area, Japan, and the United Kingdom. Journal of Economic Perspectives 32(4), 147172.

Devereux, M. B. and C. Engel (2002). Exchange rate pass-through, exchange rate volatility, and exchange rate disconnect. Journal of Monetary Economics 49(5), 913-940.

Devereux, M. B. and C. Engel (2003). Monetary policy in the open economy revisited: Price setting and exchange-rate flexibility. The Review of Economic Studies 70(4), 765-783.

Devereux, M. B. and J. Yetman (2002). Price setting and exchange rate pass-through: Theory and evidence. HKIMR Working Paper No.22/2002.

Donayre, L. and I. Panovska (2016). State-dependent exchange rate pass-through behavior. Journal of International Money and Finance 64, 170-195.

Ellis, C., H. Mumtaz, and P. Zabczyk (2014). What lies beneath? A time-varying FAVAR model for the UK transmission mechanism. The Economic Journal 124(576), 668-699.

Engel, C. (2002). The responsiveness of consumer prices to exchange rates: A synthesis of some new open economy macro models. The Manchester School $70(\mathrm{~S} 1), 1-15$.

Farrant, K. and G. Peersman (2006). Is the exchange rate a shock absorber or a source of shocks? New empirical evidence. Journal of Money, Credit and Banking, 939-961. 
Forbes, K., I. Hjortsoe, and T. Nenova (2018a). The shocks matter: Improving our estimates of exchange rate pass-through. Journal of International Economics 114, 255-275.

Forbes, K. J., I. Hjortsoe, and T. Nenova (2018b). International evidence on shock-dependent exchange rate pass-through. MIT Sloan School Working Paper 5522-18.

Fry, R. and A. Pagan (2011). Sign restrictions in structural vector autoregressions: A critical review. Journal of Economic Literature 49(4), 938-960.

Gopinath, G. (2015). The international price system. NBER Working Paper No. 21646.

Gopinath, G., O. Itskhoki, and R. Rigobon (2010). Currency choice and exchange rate passthrough. American Economic Review 100(1), 304-36.

Green, R. A., D. H. Papell, and R. Prodan (2015). Why was the Plaza Accord unique? Working Paper.

Grossman, V., E. Martínez-García, M. Wynne, and R. Zhang (2019). Ties that bind: Estimating the natural rate of interest for small open economies. Globalization and Monetary Policy Institute Working Paper No. 359.

Ha, J., M. Stocker, and H. Yilmazkuday (2019). Inflation and exchange rate pass-through. World Bank Policy Research Working Paper No. 8780.

Hamilton, J. D. (2018). Why you should never use the Hodrick-Prescott filter. Review of Economics and Statistics 100(5), 831-843.

Hara, N., K. Hiraki, and Y. Ichise (2015). Changing exchange rate pass-through in Japan: Does it indicate changing pricing behavior? Bank of Japan Working Paper 15-E-4.

Ilzetzki, E., C. M. Reinhart, and K. S. Rogoff (2019, 01). Exchange arrangements entering the twenty-first century: Which anchor will hold? The Quarterly Journal of Economics 134(2), 599-646.

Ito, T. (2005). Interventions and Japanese economic recovery. International Economics and Economic Policy 2(2-3), 219-239.

Ito, T. (2015). The Plaza Agreement and Japan: Reflections on the 30th year anniversary. Working Paper.

Ito, T. and T. Yabu (2020). Japanese foreign exchange interventions, 1971-2018: Estimating a reaction function using the best proxy. NBER Working Paper No. 26644.

Jiménez-Rodríguez, R. and A. Morales-Zumaquero (2016). A new look at exchange rate passthrough in the G-7 countries. Journal of Policy Modeling 38(5), 985-1000.

Kawamoto, T., M. Nakahama, et al. (2017). Why did the BOJ not achieve the 2 percent inflation target with a time horizon of about two years? Examination by time series analysis. Bank of Japan Working Paper Series 17-E-10. 
Kilian, L. and D. P. Murphy (2012). Why agnostic sign restrictions are not enough: Understanding the dynamics of oil market VAR models. Journal of the European Economic Association 10(5), 1166-1188.

Kilian, L. and X. Zhou (2019). Oil prices, exchange rates and interest rates. CEPR Discussion Paper No. DP13478.

Kose, M. A. (2002). Explaining business cycles in small open economies: How much do world prices matter? Journal of International Economics 56(2), 299-327.

Kose, M. A., C. Otrok, and C. H. Whiteman (2003). International business cycles: World, region, and country-specific factors. American Economic Review 93(4), 1216-1239.

Krippner, L. (2013). Measuring the stance of monetary policy in zero lower bound environments. Economics Letters 118(1), 135-138.

Lawrence, R. Z. and P. Krugman (1987). Imports in Japan: Closed markets or minds? Brookings Papers on Economic Activity 1987(2), 517-554.

Leduc, S. and Z. Liu (2016). Uncertainty shocks are aggregate demand shocks. Journal of Monetary Economics 82, 20-35.

Lombardi, M., F. Zhu, et al. (2018). A shadow policy rate to calibrate US monetary policy at the zero lower bound. International Journal of Central Banking 14(5), 305-346.

Matsumura, M. (2018). What price index should central banks target? An open economy analysis. Working Paper.

Meese, R. A. and K. Rogoff (1983). Empirical exchange rate models of the seventies: Do they fit out of sample? Journal of International Economics 14(1-2), 3-24.

Mendoza, E. G. (1995). The terms of trade, the real exchange rate, and economic fluctuations. International Economic Review, 101-137.

Monacelli, T. (2005). Monetary policy in a low pass-through environment. Journal of Money, Credit and Banking, 1047-1066.

Moussa, Z. (2016). How big is the comeback? Japanese exchange rate pass-through assessed by time-varying FAVAR. Working Paper.

Obstfeld, M. (2002). Exchange rates and adjustment: Perspectives from the new open economy macroeconomics. NBER Working Paper No. 9118.

Obstfeld, M. (2009). Time of troubles: The yen and Japan's economy, 1985-2008. NBER Working Paper No. 14816.

Rabanal, P., J. F. Rubio-Ramírez, and V. Tuesta (2011). Cointegrated TFP processes and international business cycles. Journal of Monetary Economics 58(2), 156-171. 
Rincon, H. and N. Rodríguez-Niño (2018). Nonlinear state and shock dependence of exchange rate pass through on prices. BIS Working Paper No. 690.

Rudebusch, G. D. (1998). Do measures of monetary policy in a VAR make sense? International Economic Review, 907-931.

Shambaugh, J. (2008). A new look at pass-through. Journal of International Money and Finance 27(4), 560-591.

Smets, F. and R. Wouters (2002). Openness, imperfect exchange rate pass-through and monetary policy. Journal of Monetary Economics 49(5), 947-981.

Sutherland, A. (2005). Incomplete pass-through and the welfare effects of exchange rate variability. Journal of International Economics 65(2), 375-399.

Takagi, S. (2007). Managing flexibility: Japanese exchange rate policy, 1971-2007. The Singapore Economic Review 52(03), 335-361.

Uhlig, H. (2005). What are the effects of monetary policy on output? Results from an agnostic identification procedure. Journal of Monetary Economics 52(2), 381-419.

Wynne, M. and R. Zhang (2018a). Estimating the natural rate of interest in an open economy. Empirical Economics 55, 1291-1318.

Wynne, M. A. and R. Zhang (2018b). Measuring the world natural rate of interest. Economic Inquiry 56(1), 530-544.

Zhang, R. (2019). News shocks and the effects of monetary policy. Working Paper available at SSRN 3348466. 


\section{Table 1: Identification Restrictions}

\begin{tabular}{lcccccc}
\hline \hline & $\begin{array}{c}\text { Japan } \\
\text { supply } \\
\text { shock }\end{array}$ & $\begin{array}{c}\text { Japan } \\
\text { demand } \\
\text { shock }\end{array}$ & $\begin{array}{c}\text { Japan } \\
\text { monetary } \\
\text { shock }\end{array}$ & $\begin{array}{c}\text { Exchange } \\
\text { rate } \\
\text { shock }\end{array}$ & $\begin{array}{c}\text { Persist } \\
\text { FP } \\
\text { shock }\end{array}$ & $\begin{array}{c}\text { Transit } \\
\text { sP }\end{array}$ \\
\hline IP & + & $+\& 0^{L}$ & $-\& 0^{L}$ & $0^{L}$ & & \\
Consumer prices & - & + & - & - & \\
Interest rate & & + & + & - & \\
Exchange rate & & + & + & + & \\
Import prices & & & & & \\
Foreign export prices & $0 \& 0^{L}$ & $0 \& 0^{L}$ & $0 \& 0^{L}$ & $0 \& 0^{L}$ & + & $+\& 0^{L}$ \\
\hline
\end{tabular}

Notes: A "+" ("-") sign indicates that the impulse response of the variable is restricted to be positive (negative) in the month the shock occurs. A "0" indicates that the response of the variable is restricted to be zero on impact. A " 0 " indicates that the response of the variable is restricted to be zero in the long run. "Persist FP" is an abbreviation for persistent foreign export price shock while "Transit FP" is an abbreviation for transitory foreign export price shock. 


\section{Table 2: Forecast Error Variance Decomposition Based on Traditional Identification Approach}

\begin{tabular}{llllllll}
\hline Variable & Horizons & Supply & Demand & Monetary Policy & Exchange Rate & Persist FP & Transit FP \\
\hline \multirow{2}{*}{ IP } & 1 & 17.61 & 4.79 & 1.96 & 4.20 & 41.08 & 30.36 \\
Consumer prices & 1 & 16.99 & 8.05 & 4.77 & 6.99 & 36.78 & 26.42 \\
& 60 & 14.77 & 19.56 & 39.55 & 21.69 & 2.29 & 2.14 \\
Interest rate & 1 & 14.47 & 17.76 & 35.48 & 20.93 & 5.57 & 5.79 \\
& 60 & 22.76 & 22.14 & 24.25 & 22.95 & 5.94 & 5.26 \\
Exchange rate & 1 & 25.67 & 30.16 & 10.90 & 24.14 & 7.61 & 10.69 \\
Import prices & 60 & 24.02 & 28.25 & 11.96 & 27.93 & 2.54 & 2.79 \\
Foreign export & 1 & 10.81 & 37.20 & 10.24 & 26.82 & 4.32 & 4.63 \\
prices & 1 & 11.73 & 33.71 & 10.99 & 25.46 & 3.16 & 11.13 \\
& 60 & 0.51 & 0.90 & 0.75 & 0.65 & 4.96 & 13.12 \\
& & 2.38 & 2.77 & 3.06 & 2.34 & 37.44 & 59.74 \\
\end{tabular}

Notes: The forecast error variance decomposition is the average of the 10,000 variance decompositions acquired from the accepted draws that satisfy the traditional sign and zero restrictions described in Table 1. "Persist FP" is an abbreviation for persistent foreign export price shock, while "Transit FP" is an abbreviation for transitory foreign export price shock.

\section{Table 3: Forecast Error Variance Decomposition Based on Narrative Sign Approach}

\begin{tabular}{llllllll}
\hline Variable & Horizons & Supply & Demand & Monetary Policy & Exchange Rate & Persist FP & Transit FP \\
\hline IP & 1 & 19.74 & 4.53 & 1.85 & 5.33 & 37.53 & 31.03 \\
& 60 & 18.72 & 7.61 & 5.14 & 7.56 & 34.05 & 26.91 \\
Consumer prices & 1 & 16.44 & 30.16 & 43.66 & 4.92 & 2.29 & 2.52 \\
& 60 & 15.40 & 26.22 & 38.79 & 6.96 & 6.22 & 6.40 \\
Interest rate & 1 & 25.23 & 22.90 & 26.07 & 10.70 & 8.05 & 7.06 \\
& 60 & 19.51 & 15.14 & 22.71 & 17.90 & 9.76 & 14.98 \\
Exchange rate & 1 & 10.49 & 12.18 & 5.71 & 68.14 & 1.86 & 1.62 \\
& 60 & 10.69 & 12.57 & 7.35 & 62.05 & 3.84 & 3.51 \\
Import prices & 1 & 6.11 & 28.10 & 10.77 & 38.87 & 2.38 & 13.76 \\
Foreign export & 60 & 7.53 & 25.93 & 11.66 & 35.02 & 4.36 & 15.50 \\
prices & 1 & 0.41 & 1.06 & 0.69 & 0.43 & 39.71 & 57.70 \\
\hline
\end{tabular}

Notes: The forecast error variance decomposition is the average of the 1,491 variance decompositions acquired from the accepted draws that satisfy the narrative sign restrictions, zero restrictions, and traditional sign restrictions described in Table 1. "Persist FP" is an abbreviation for persistent foreign export price shock, while "Transit FP" is an abbreviation for transitory foreign export price shock. 
Figure 1: Chronology of the Bilateral Exchange Rate of the Yen

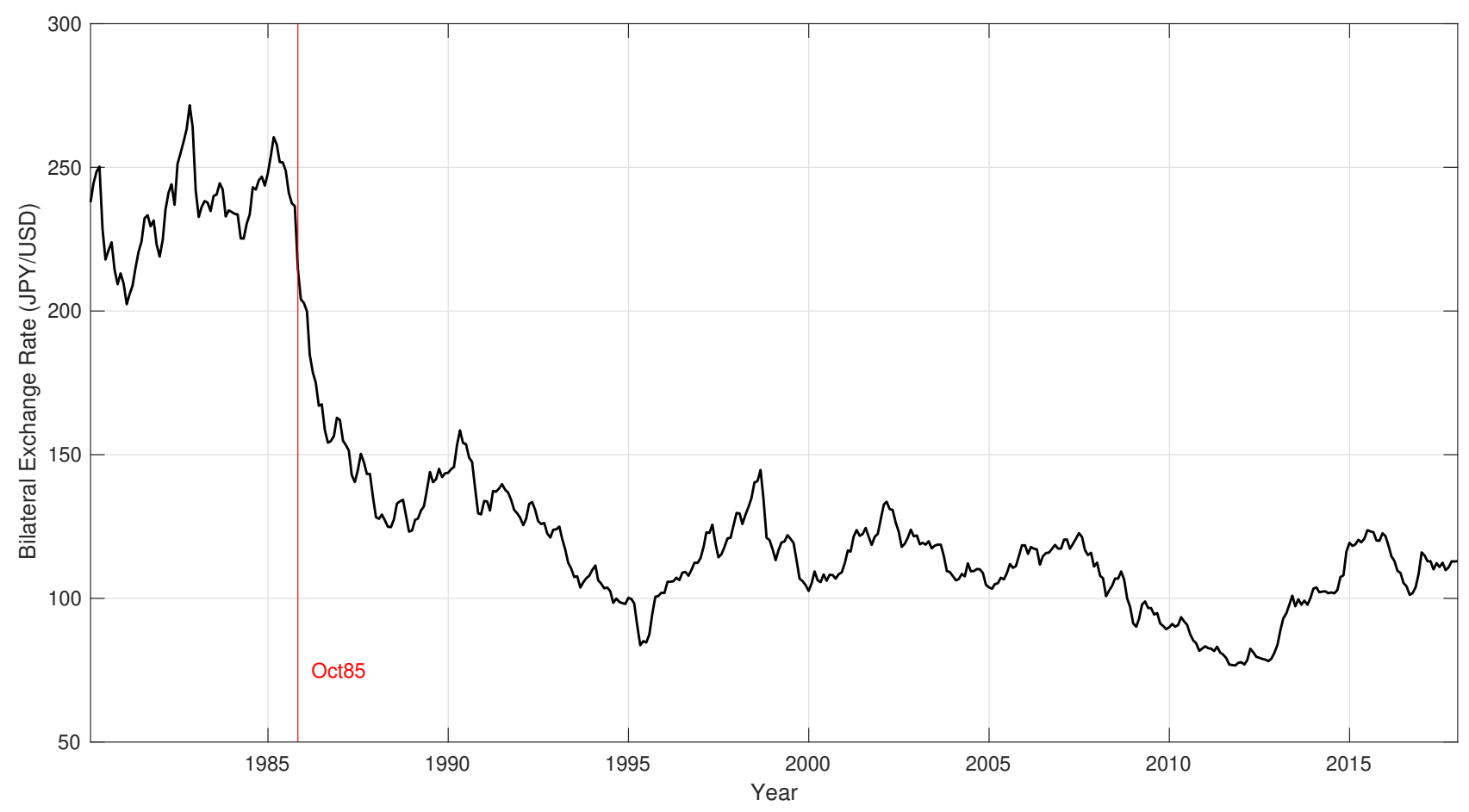

Notes: The black line plots the monthly bilateral exchange rate between the yen and the U.S. dollar from 1980 to 2017. The red vertical bar indicates the Plaza Accord episode. 


\section{Figure 2: Impluse Responses for Supply Shock, Demand Shock and Monetary Policy Shock}
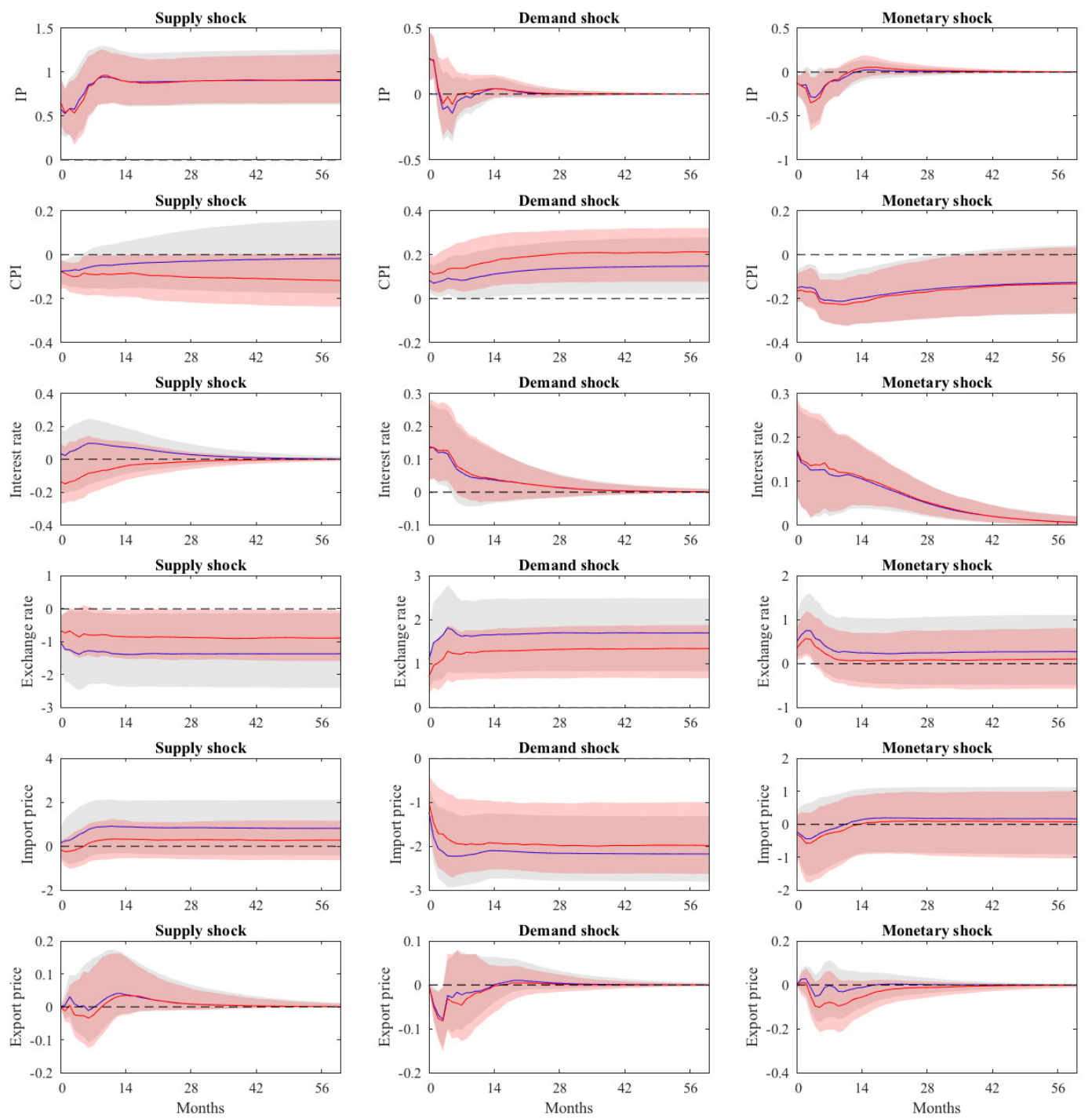

Notes: The gray shaded areas represent the $68 \%$ (point-wise) confidence bands for the impulse responses and the blue lines are the median impulse responses using the traditional sign and zero identification approach. The red shaded areas and the red lines display the equivalent quantities for the models that additionally satisfy narrative sign restrictions. 


\section{Figure 3: Impulse Responses for Exchange Rate Shock and Foreign Export Price Shocks}
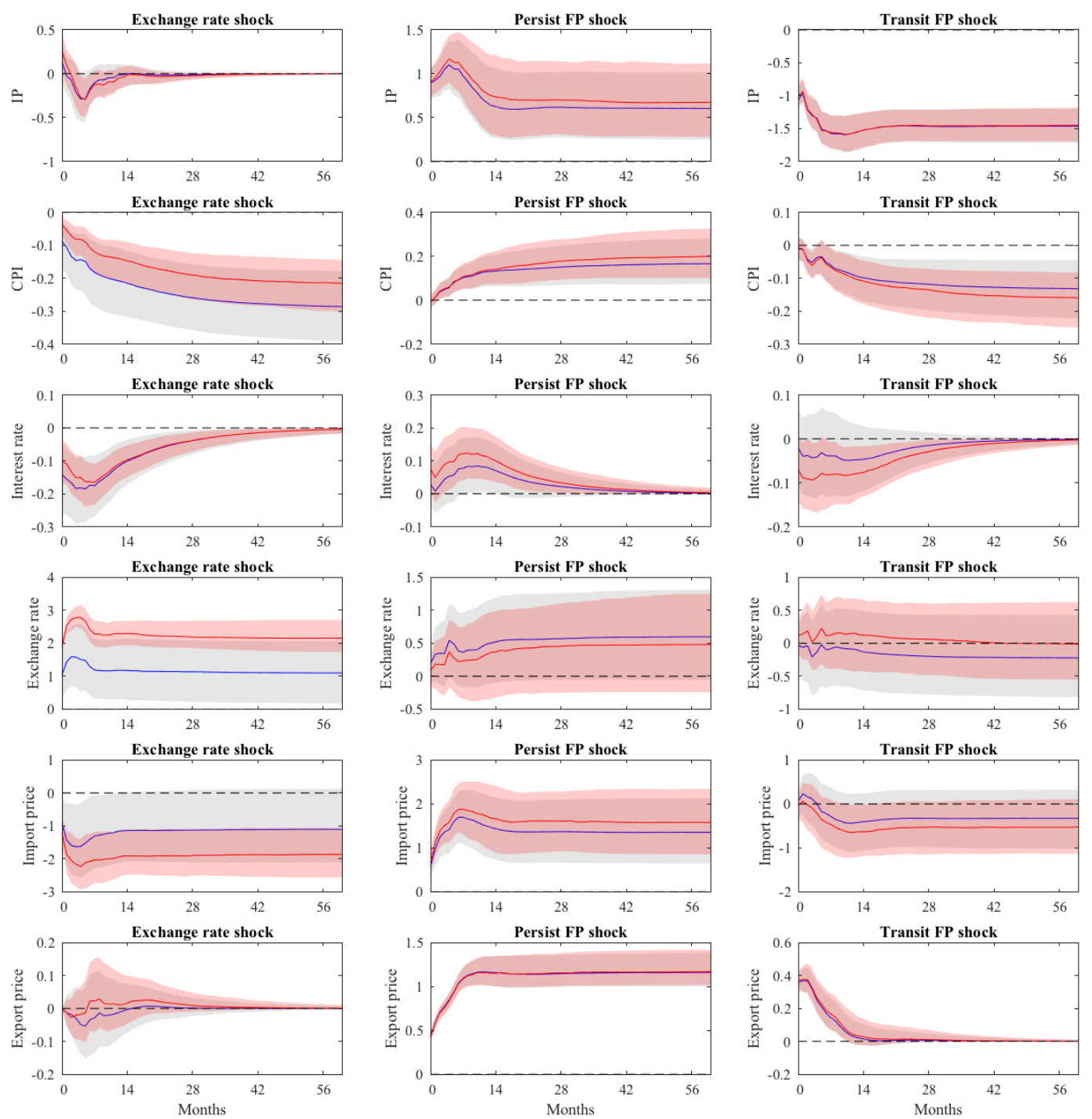

Notes: The gray shaded areas represent the $68 \%$ (point-wise) confidence bands for the impulse responses and the blue lines are the median impulse responses using the traditional sign and zero identification approach. The red shaded areas and the red lines display the equivalent quantities for the models that additionally satisfy narrative sign restrictions. "Persist FP" is an abbreviation for persistent foreign export price shock while "Transit FP" is an abbreviation for transitory foreign export price shock. 


\section{Figure 4: Exchange Rate Shock Distribution and Counterfactual Ex- change Rate}

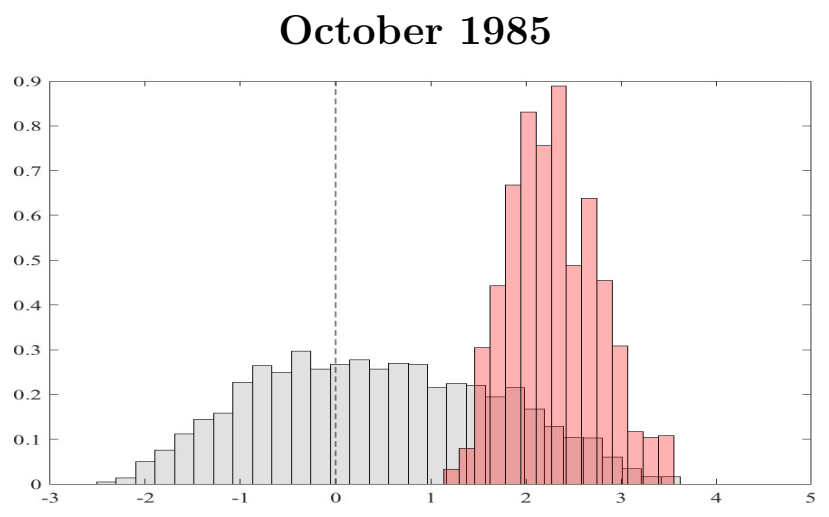

July 1989

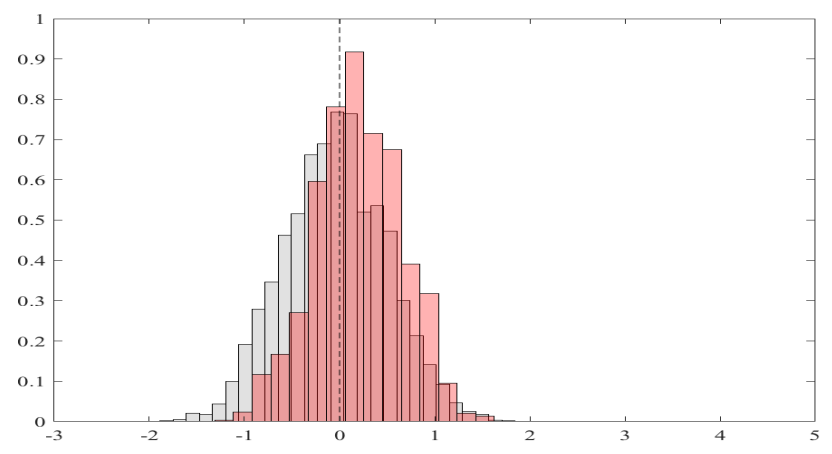

March 2004

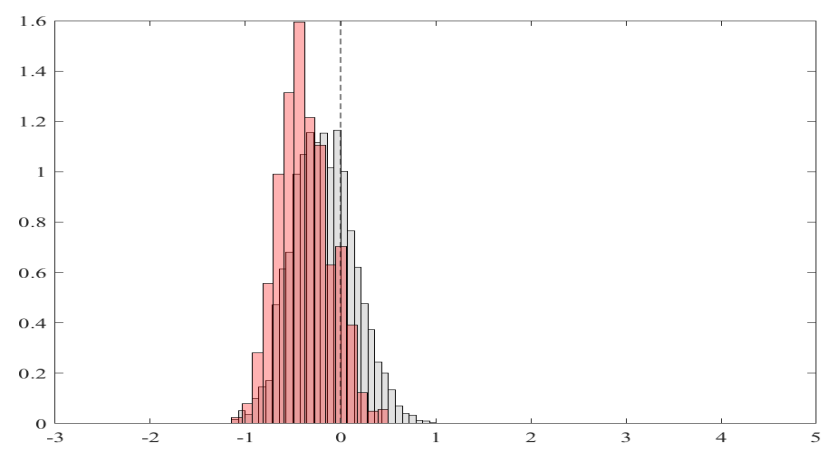

October 1985

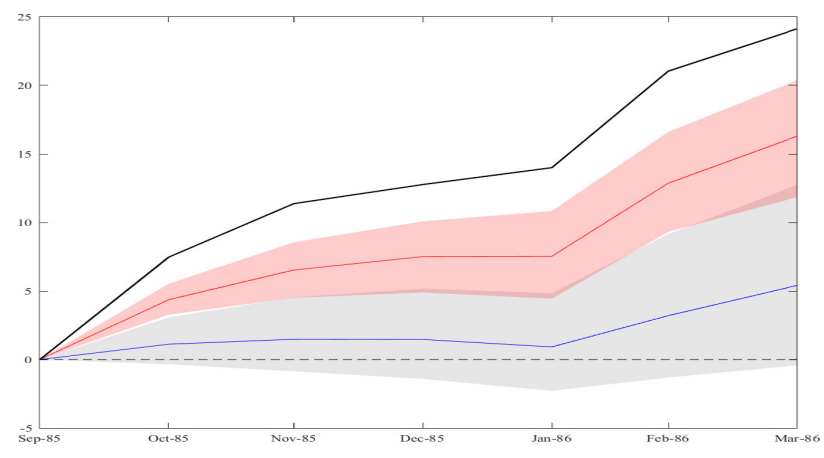

July 1989

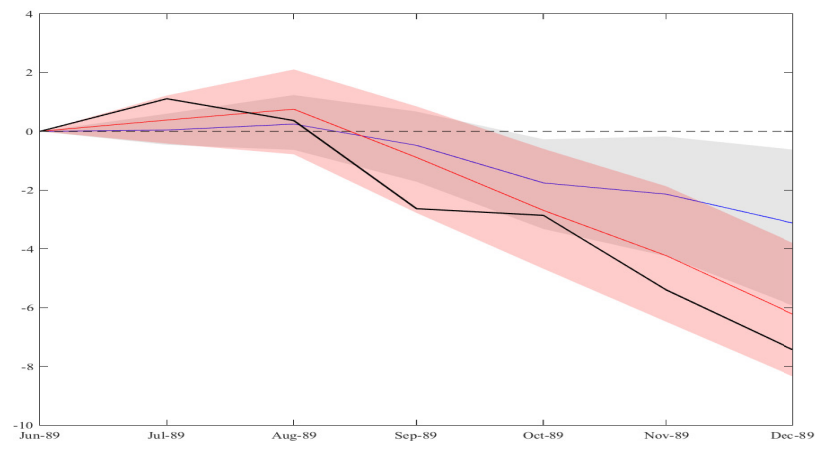

March 2004

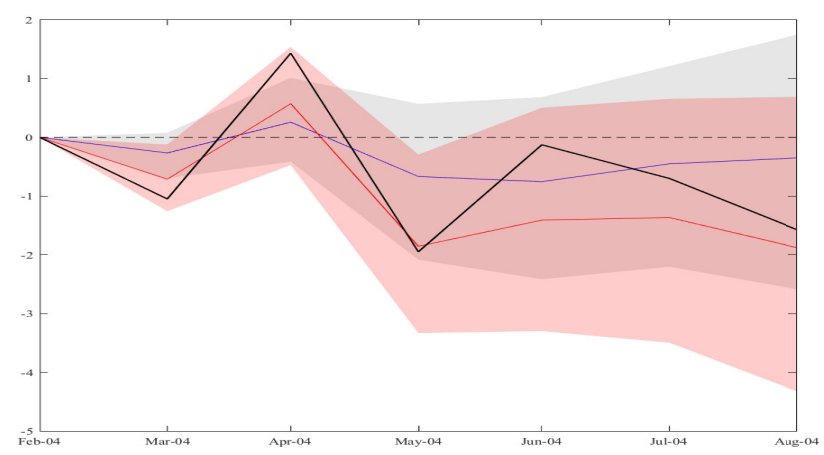

Notes: The left panels plot the exchange rate shock distributions for three different historical episodes. The gray histogram plots the posterior distributions of the exchange rate shock using the traditional identification approach. The red histogram plots the same distributions after incorporating the narrative sign restrictions. The right panels show the counterfactual exchange rate paths for the same three periods. The solid thick line indicates the actual exchange rate movement, the gray shaded area corresponds to $68 \%$ credible sets around the median of the counterfactual exchange rate if no other structural shock other than the specific shock had occurred using the traditional identification. The solid red thin line and red shaded area plot the same results using the narrative sign restrictions. 


\section{Figure 5: Exchange Rate Pass-Through to Import Prices}
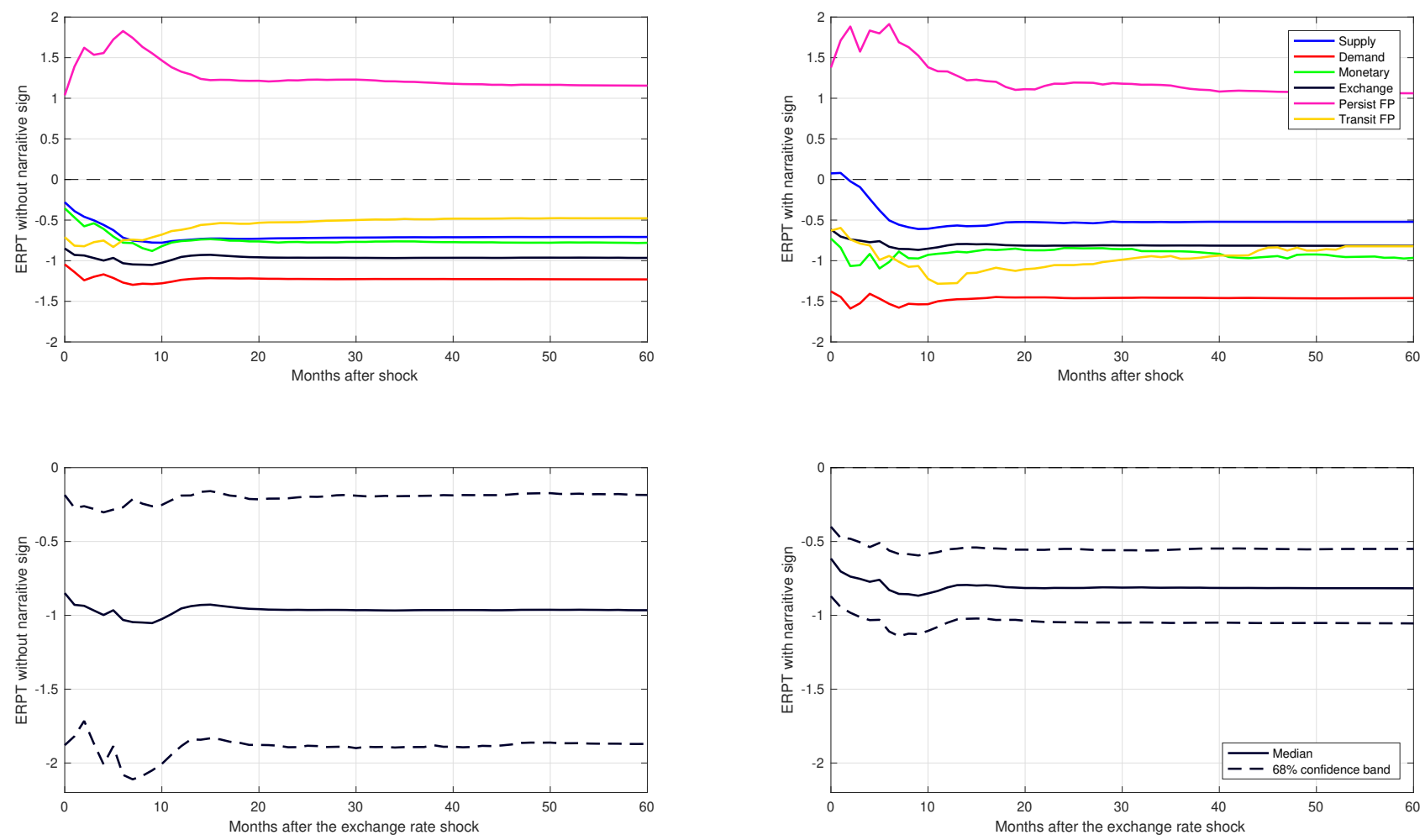

Notes: The upper left panel reports the median ERPT ratio, defined as the cumulative impulse response of import prices relative to the exchange rate, following each of the six structural shocks identified with only the traditional sign and zero restrictions. The upper right panel reports the median ERPT ratio following all of the six structural shocks identified with the narrative sign restrictions in addition to the traditional sign and zero restrictions. "Persist FP" is an abbreviation for persistent foreign export price shock while "Transit FP" is an abbreviation for transitory foreign export price shock. The lower panels show the median ERPT ratio (solid lines) and the associated $68 \%$ confidence bands (dashed lines) to the identified exogenous exchange rate shock. 


\section{Figure 6: Exchange Rate Pass-Through to CPI}
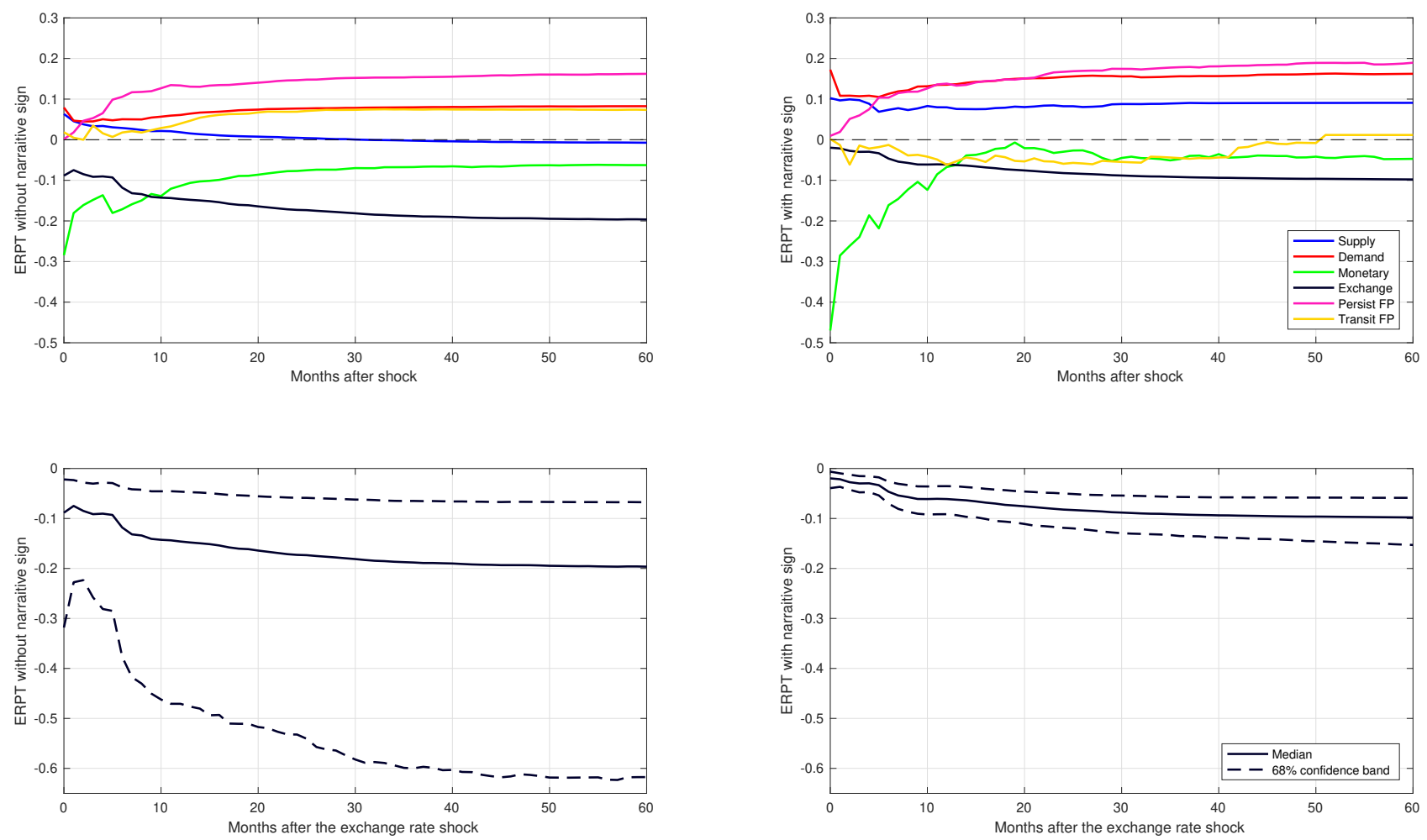

Notes: The upper left panel reports the median ERPT ratio, defined as the cumulative impulse response of CPI relative to the exchange rate, following each of the six structural shocks identified with only the traditional sign and zero restrictions. The upper right panel reports the median ERPT ratio following all of the six structural shocks identified with the narrative sign restrictions in addition to the traditional sign and zero restrictions. "Persist FP" is an abbreviation for persistent foreign export price shock while "Transit FP" is an abbreviation for transitory foreign export price shock. The lower panels show the median ERPT ratio (solid lines) and the associated $68 \%$ confidence bands (dashed lines) to the identified exogenous exchange rate shock. 


\title{
Figure 7: Historical Decomposition of Year-on-Year Changes in Nom- inal Exchange Rate
}

\author{
Traditional Identification
}

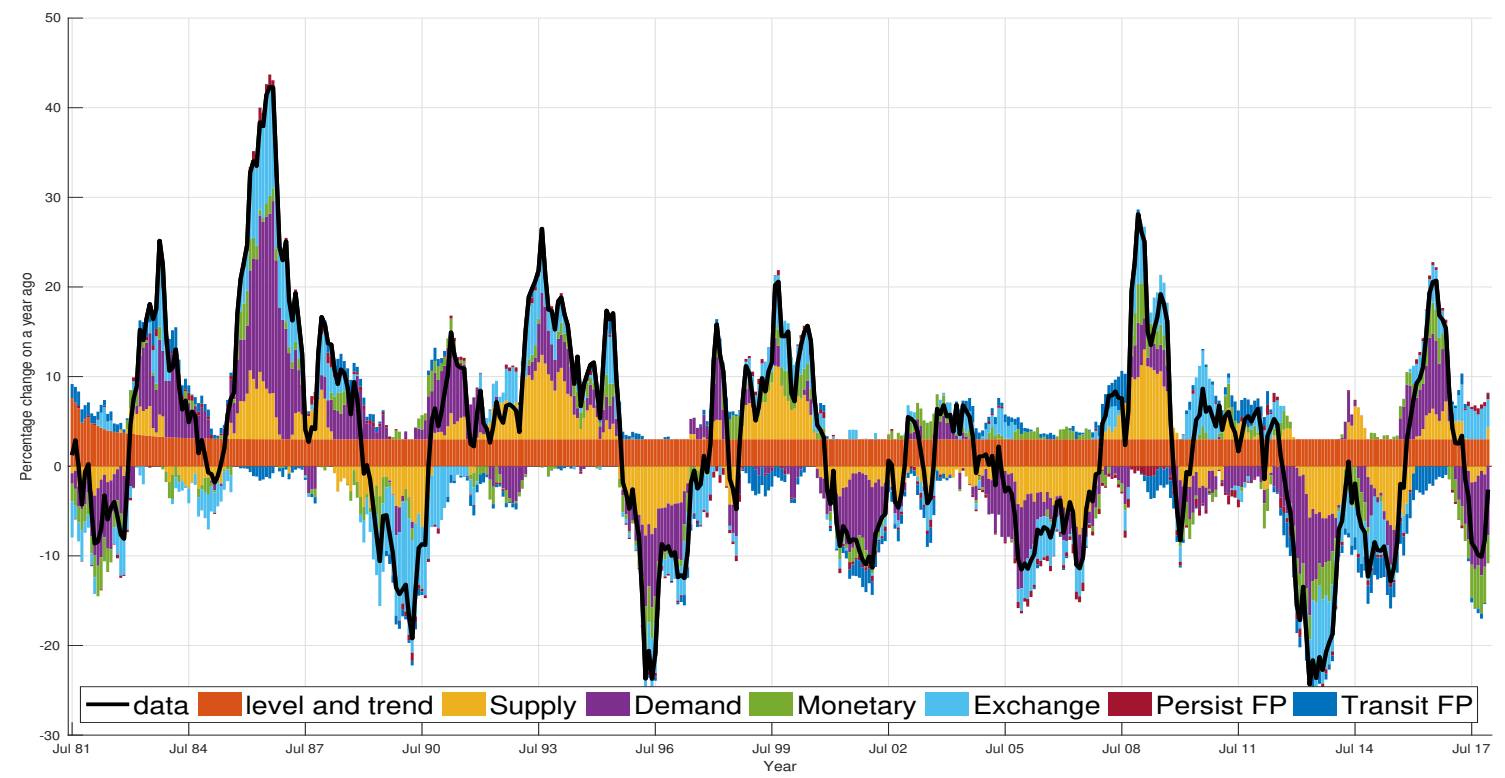

Narrative Sign Restriction

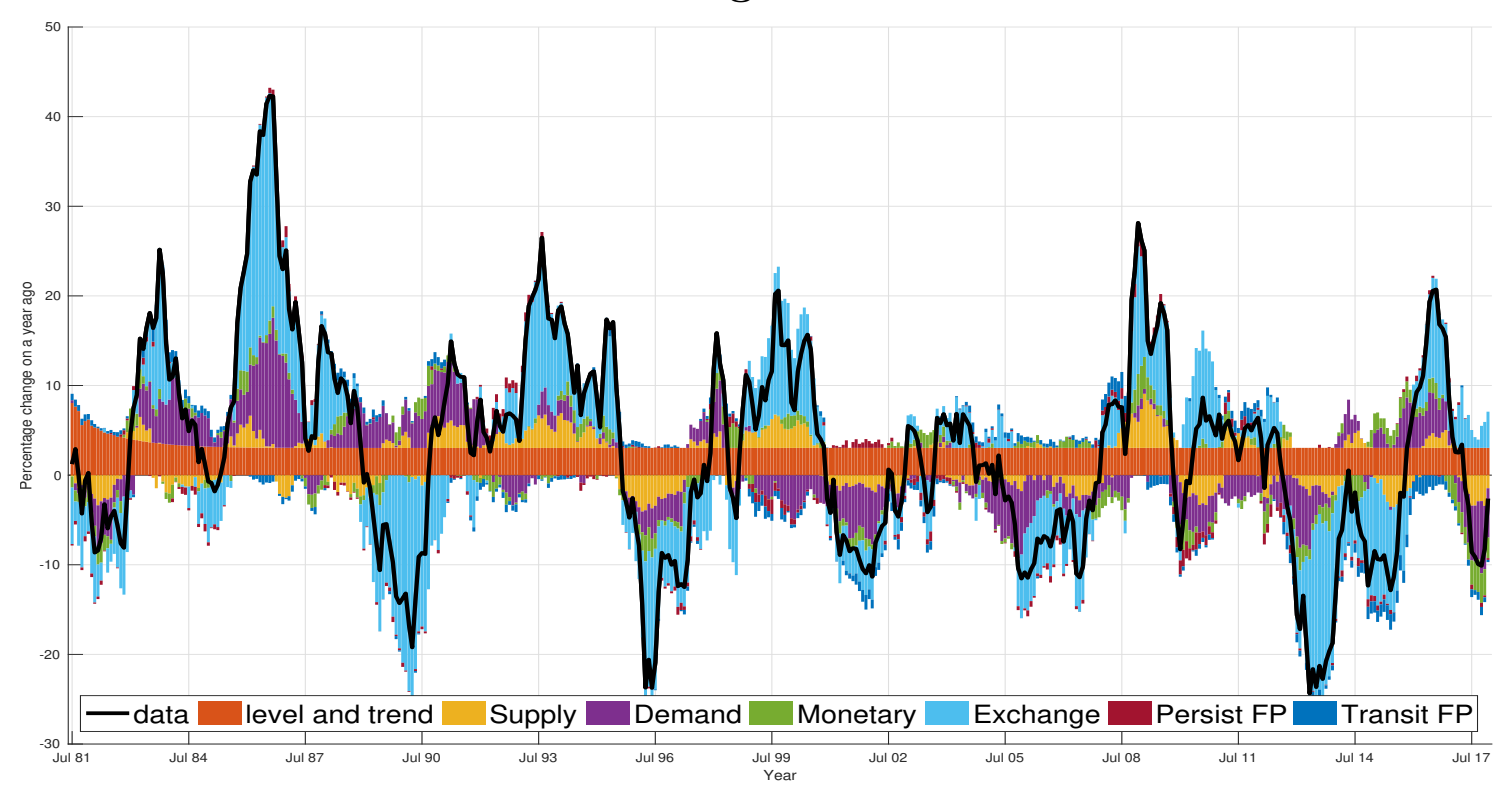

Notes: The upper panel shows the contribution of each of the six shocks to y/y growth rate in the effective exchange rate implied by the traditional identification approach. The displayed historical decompositions are the averages of the 10,000 historical decompositions satisfying the traditional sign and zero restrictions. The lower panel depicts the contribution of the six narrative sign identified shocks to $\mathrm{y} / \mathrm{y}$ growth rate in the effective exchange rate. The displayed historical decompositions are the averages of the 1,491 historical decompositions satisfying the zero, traditional sign and narrative sign restrictions. 


\title{
Figure 8: Historical Decomposition of Year-on-Year Changes in Import Prices
}

\author{
Traditional Identification
}

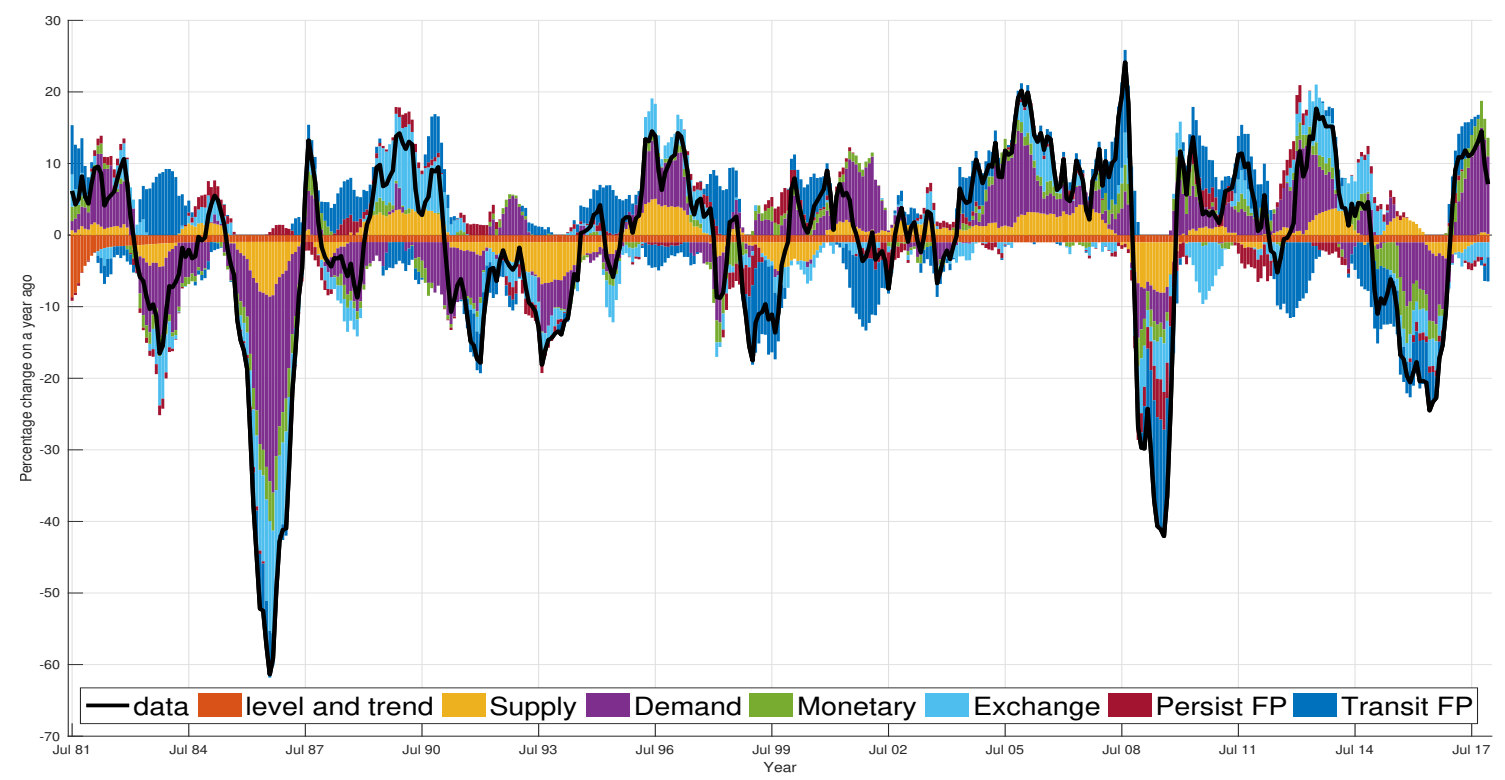

\section{Narrative Sign Restriction}

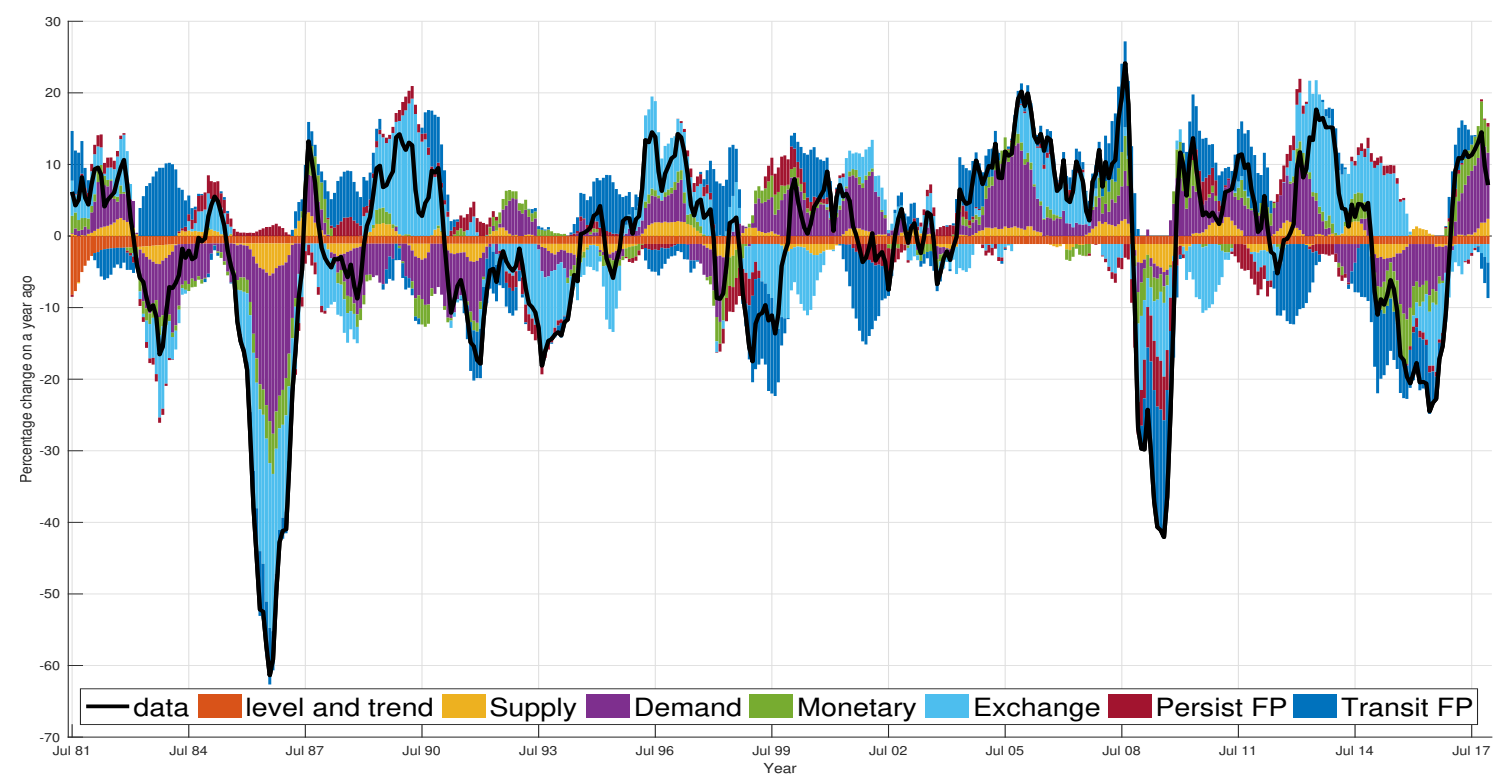

Notes: The upper panel shows the contribution of each of the six shocks to $\mathrm{y} / \mathrm{y}$ growth rate in the effective exchange rate implied by the traditional identification approach. The displayed historical decompositions are the averages of the 10,000 historical decompositions satisfying the traditional sign and zero restrictions. The lower panel depicts the contribution of the six narrative sign identified shocks to y/y growth rate in the effective exchange rate. The displayed historical decompositions are the averages of the 1,491 historical decompositions satisfying the zero, traditional sign and narrative sign restrictions. 
Figure 9: Time-varying ERPT in Japan Based on the Identified Shocks

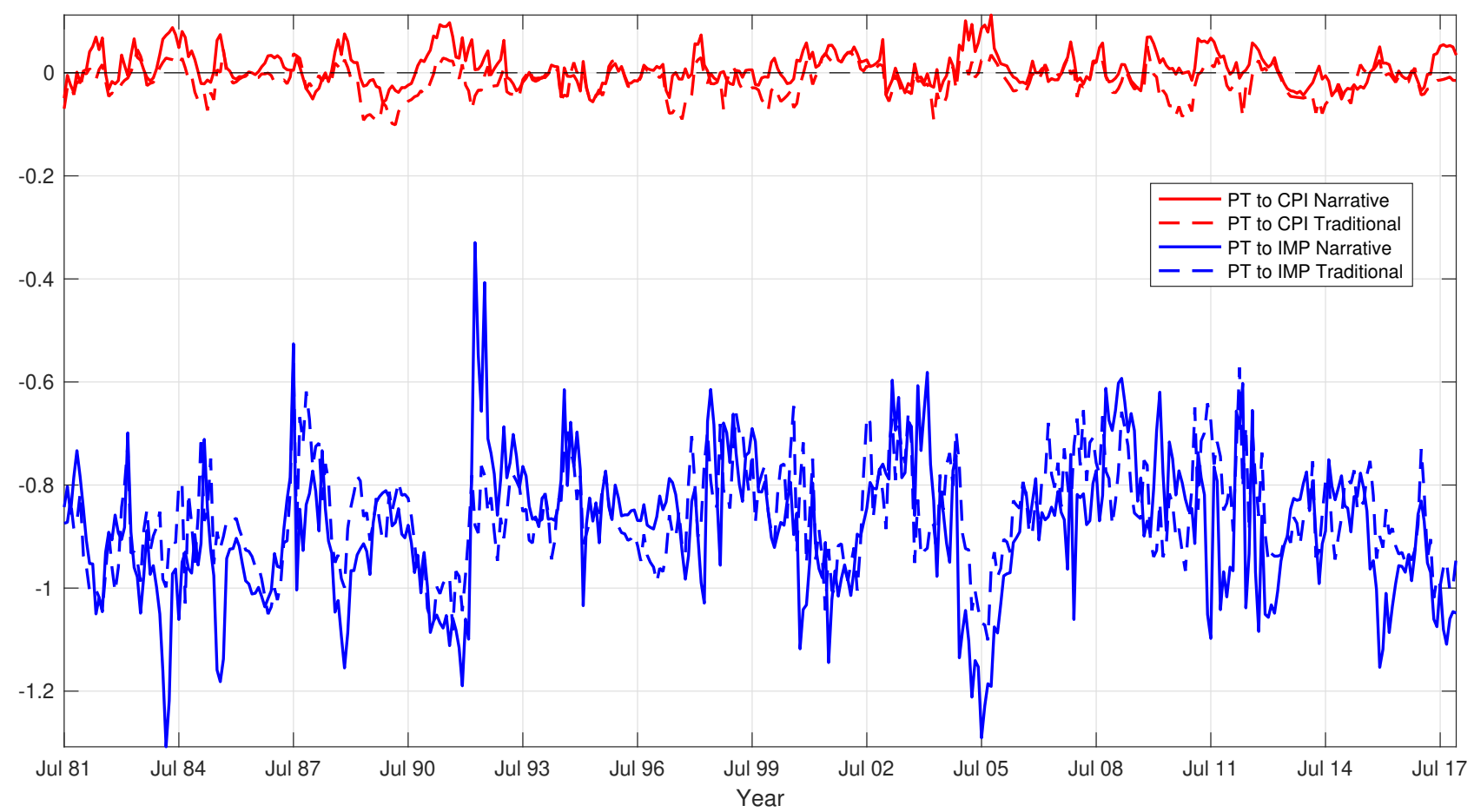

Notes: The blue solid line ("PT to IMP Narrative") plots the time-varying ERPT ratio to import prices by computing the weighted average of the shock-dependent ERPT ratio identified by the narrative sign approach. The weights are set based on the historical decomposition of the exchange rate growth. The blue dashed line ("PT to IMP Traditional') displays the corresponding ratio to import prices implied by the traditional identification approach. The red solid line ("PT to CPI Narrative") and the red dashed line ("PT to CPI Traditional") show the ERPT ratio to CPI implied by, respectively, the narrative sign approach and the traditional identification strategy. 


\section{Figure 10: Structural Scenario Analysis}
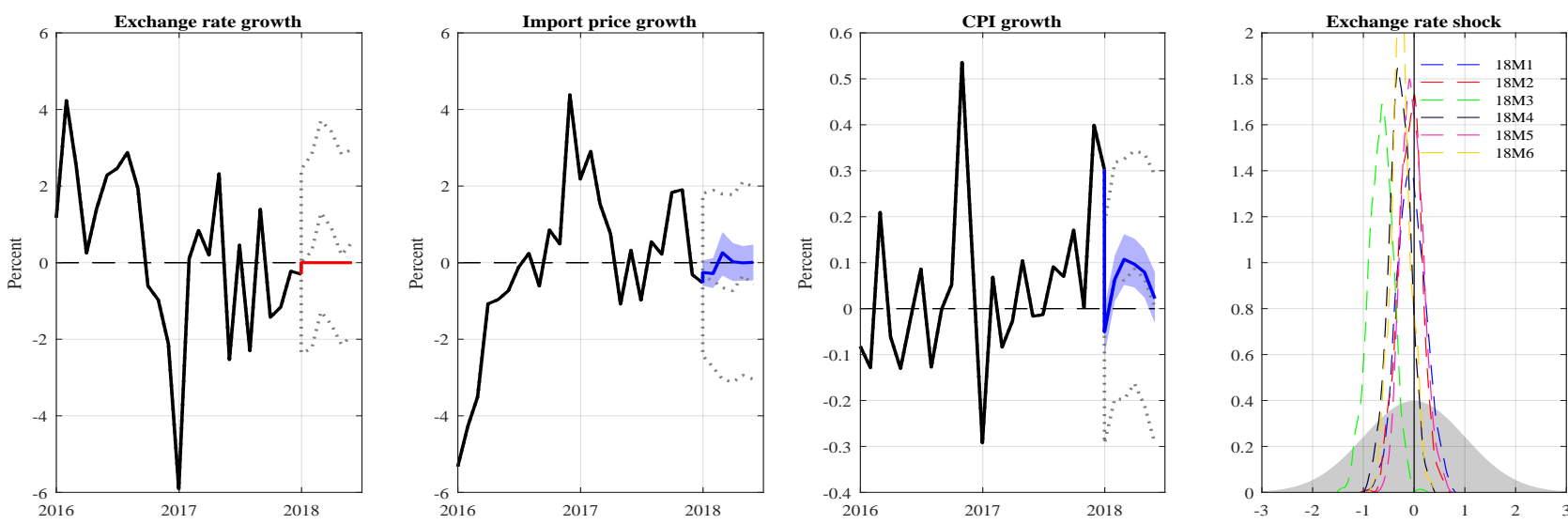

(b) Stable Import Price Inflation
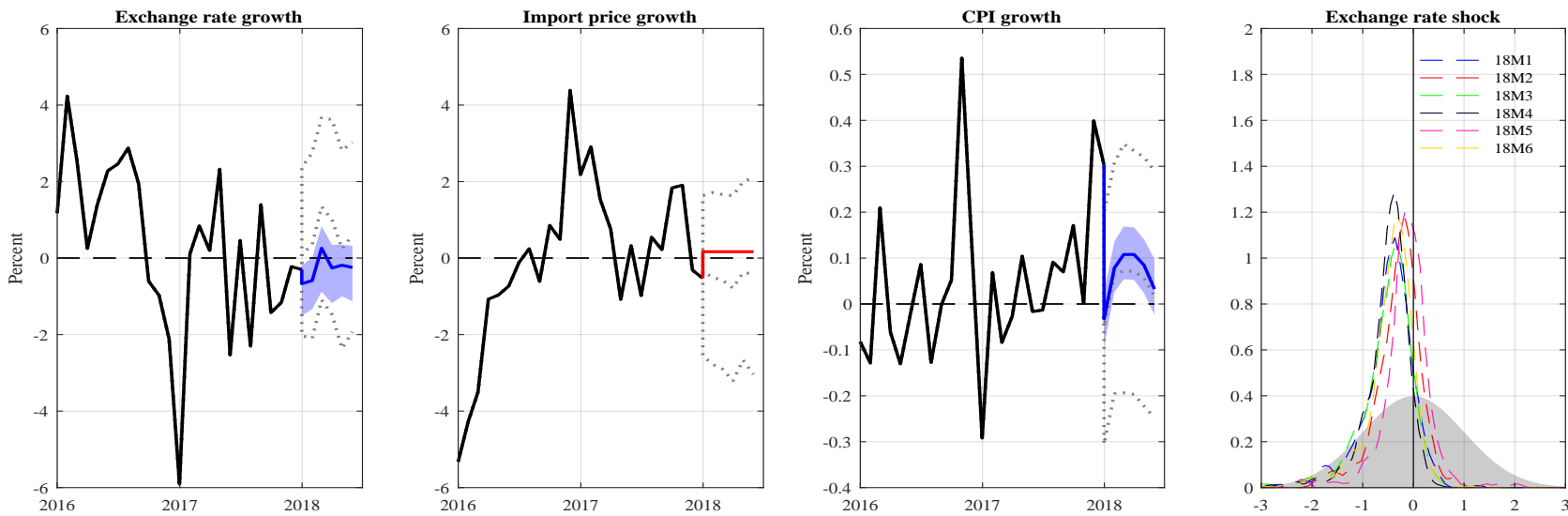

Notes: For the left three panels in each row, the solid black lines display actual data, the solid red lines denote the conditioning assumptions on the observables, the solid blue lines represent the median forecast for the other variables in the next six months, and the blue shaded areas depict the $68 \%$ pointwise credible sets around the median forecasts. The dotted black lines outline the median and the shapes of the $68 \%$ credible sets around the unconditional forecasts. The last panel in each row shows the probability density functions of the structural shocks implied by the conditional forecasting and structural scenario analysis for every $t=T+1 \ldots T+6$. The gray shaded areas are the probability density functions of a standard normal distribution. 